Alma Mater Studiorum - Università di Bologna DEPARTMENT OF ECONOMICS

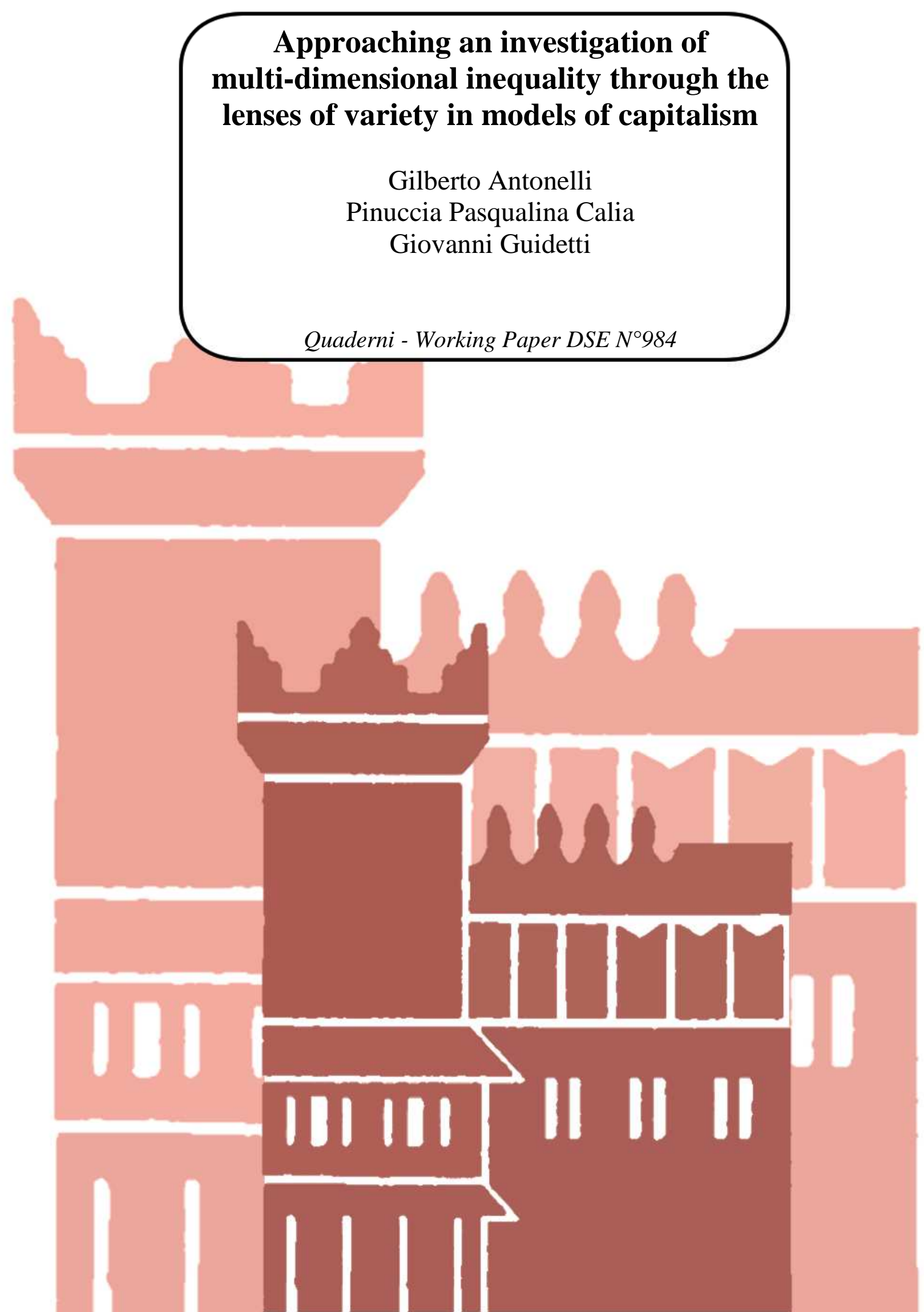




\title{
Approaching an investigation of multi-dimensional inequality through the lenses of variety in models of capitalism
}

\author{
Gilberto Antonelli ${ }^{\mathrm{a}}$, Pinuccia Pasqualina Calia ${ }^{\mathrm{b}}$, Giovanni Guidetti $^{\mathrm{c}}$
}

\begin{abstract}
After a synthetic presentation of the state of poverty and inequality in the world and the contradictions incurred by economic theory in this field after decades of globalization and in the midst of a persisting global crisis, in paragraphs 2. and 3. we outline the rational for our theoretical analysis, underlining two main aspects. First of all, in paragraph 2 . we recall the reasons which makes inequality a multidimensional phenomenon, while in paragraph 3 . we explore the reasons why the models of capitalism theory is relevant for studying multidimensional inequality. These paragraphs emphasise that inequality is a multidimensional and cumulative phenomenon and it should not be conceived only as the result of the processes of personal and functional distribution of income and wealth, which even by themselves are intrinsically multidimensional. The basic idea is that institutions, the cobweb of relations among them and their interaction with the economic structure define the model of capitalism which characterises a specific country and this, in turn, affects the level and the dynamics of inequality. This approach is consistent with the sociological approach by Rehbein and Souza (2014), based on the analytical framework developed by Pierre Bourdieu.

In paragraph 4. we outline the rational for our empirical analysis, applying the notion of institutional complementarity and examining the relationship between institutional complementarity, models of capitalism and inequality. Besides, refining Amable's analysis (2003), we provide empirical evidence on the relationship between inequality in income distribution and models of capitalism. Additionally, basing on cluster analysis, we identify six different models of capitalism in a sample of OECD countries, provide preliminary evidence on the different level of inequality which characterises each model and suggest that no evidence supports of the idea that a single model of capitalism is taking shape in this sphere in EU.

In paragraph 5. we give some hints about issues in search for a new interpretation capable to fasten together the process of increasing inequality, the notion of symbolic violence and the models of capitalism theory.

In the last paragraph we focus on conclusions useful for carrying on our research agenda.
\end{abstract}

Keywords: multidimensional inequality, poverty, models of capitalism, cluster analysis, institutions, economic structure, complementarity.

JEL classification P16 (Political economy), B52 (current heterodox approaches: institutional, evolutionary).

\footnotetext{
a Department of Economics, University of Bologna; School of Development Innovation and Change (SDIC). gilberto.antonelli@unibo.it

$\mathrm{b}$ Department of Statistical Sciences "Paolo Fortunati", University of Bologna. Pinuccia Pasqualina Calia <pinuccia.calia@unibo.it>

c Department of Economics, University of Bologna; School of Development Innovation and Change (SDIC). Corresponding author: Giovanni Guidetti <g.guidetti@unibo.it>
} 


\section{Introduction}

The state of poverty and inequality in the world after decades of globalization and in the midst of a persisting global crisis is openly disclosed by UNDP $(2013,2014)$. While some fragile success has been achieved in terms of extreme poverty ${ }^{1}$, relative poverty ${ }^{2}$ and inequality looks out of control.

At the world level the extreme or absolute poverty rate fell in 2010 to less than half the 1990 rate. The 1.A. target of the Millennium Development Goals was met five years ahead of the 2015 deadline. This implies that 700 million fewer people lived in conditions of extreme poverty in 2010 than in 1990. As suggested in the Report by UNDP (2013, p. 1), this result has been fostered by "impressive average gains against multiple indicators of material prosperity." 3

Nevertheless, at the global level 1.2 billion people are still living in extreme poverty, with different trajectories in the different world regions.

Moreover, if we truly think that poverty is a multi-dimensional and cumulative phenomenon, the overall scenario becomes more fuzzy and alarming. Following $\operatorname{UNDP}$ (2014, p. 3) "Those living in extreme poverty and deprivation are among the most vulnerable. Despite recent progress in poverty reduction, more than 2.2 billion people are either near or living in multidimensional poverty. That means more than 15 percent of the world's people remain vulnerable to multidimensional poverty. At the same time, nearly 80 percent of the global population lack comprehensive social protection. About 12 percent (842 million) suffer from chronic hunger, and nearly half of all workers - more than 1.5 billion - are in informal or precarious employment."

When we come to consider recent trends in inequality the scenario get even worse. "The richest 1 percent of the world population owns about 40 percent of the world's assets, while the bottom half owns no more than 1 percent. Despite overall declines in maternal mortality, women in rural areas are still up to three times more likely to die while giving birth than women living in urban centres. Social protection has been extended, yet persons with disabilities are up to five times more likely than average to incur catastrophic health expenditures. Women are participating more in the work force, but continue to be disproportionately represented in vulnerable employment. Humanity remains deeply divided."

The optimistic scenario anticipated at the end of last Century by mainstream economists ${ }^{5}$ and international organizations ${ }^{6}$ has been radically overturned. Globalisation used to be thought good for the poor, the unemployed and the middle-class. But, the impact of the global crisis has deeply challenged this view, fostering new interest for inequality in policy makers, citizens and social scientists. And now the balance is bluntly described as follows.

"Over the last two decades, income inequality has been growing on average within and across countries. As a result, a significant majority of the world's population lives in societies that are more unequal today than 20 years ago. ... In fact, the sharpest increases in income inequality have occurred in those developing countries that were especially successful in pursuing vigorous growth and managed, as a result, to graduate into higher income brackets. Economic progress in these countries has not alleviated disparities, but rather exacerbated them. ... there are clear signs that this situation cannot be sustained for much longer. Inequality has been jeopardizing economic growth and poverty reduction. It has been stalling progress in education, health and nutrition for large swathes of the population, thus undermining the very human capabilities necessary for achieving a

\footnotetext{
${ }^{1}$ In the past, the absolute poverty line at the international level was next to $\$ 1$ a day. From 2008 it has been revised by World Bank to $\$ 1.25$ a day at 2005 purchasing-power parity.

${ }^{2}$ Measuring relative poverty is akin to measuring income inequality, since it is related to the overall distribution of income or consumption in a country; for example, in OECD and EU the relative poverty line is set at an income level which is at $60 \%$ of the median household income.

${ }^{3}$ Per capita GDP in low- and middle-income countries has more than doubled in real terms since 1990. In the same period, life expectancy in developing countries has risen from 63.2 years to 68.6 years.

${ }^{4}$ Jessé Souza (2011) would probably include these persons in what he calls the "underclass".

${ }^{5}$ See for instance Sala-i-Martin (2002).

${ }^{6}$ The reference goes, for instance, to the s.c. 'Washington consensus' view and the Davos World Economic Forum, especially in the 1971-2004 editions.
} 
good life. It has been limiting opportunities and access to economic, social and political resources. Furthermore, inequality has been driving conflict and destabilizing society. When incomes and opportunities rise for only a few, when inequalities persist over time and space and across generations, then those at the margins, who remain so consistently excluded from the gains of development, will at some point contest the 'progress' that has bypassed them. ... But perhaps most important, extreme inequality contradicts the most fundamental principles of social justice, starting from the notion, enshrined in the Universal Declaration of Human Rights, that "all human beings are born free and equal in dignity and rights"”. (UNDP, 2013, p. 1)

Of course poverty and inequality are very different, even if not unrelated, concepts. The mainstream view oversimplifies the issue: "While it is unanimously agreed that poverty is bad, it is less clear that income inequalities are undesirable. After all, increases in inequality can arise from the worsening of the poor (a situation that is clearly bad) or the improvement of the rich (a situation that is clearly not bad)." (Sala-i-Martin, 2002, p. 1)

Following this way of reasoning, it is rather common to distinguish between inequality in opportunities and inequality in outcomes. Much of the debate in development theory has been structured along these lines: the first is primarily concerned with factors that inhibit equitable outcomes, such as unequal access to employment or education; and the second with factors which influence the level achieved in various material dimensions of human success, such as income or education. While the latter is regarded as a standard result of economic and social life, and particularly of the competitive game, the former begets disapproval as an infringement of democratic principles.

In any case, every judgement on inequality is extremely diverse for at least four indirect reasons. (a) Economies are going through deep transformations that are affected by outsourcing/unboundling and networks/value chains restructuring. (b) Economic and social classes are at the same time more and more fragmented, but less and less recognizable on account of specific roles performed in economic systems (and society in general). A range of income sources is available for the average worker, but these sources are not anymore necessarily linked to the factors of production the individual is endowed with. (c) Welfare perspectives vary according to the position held by the single agent in the household, in the society and in the networks in which she/he lives. (d) Different social and economic models of capitalism score rather different end results.

At the same time, different layers of inequality are altogether relevant: (i) intra and inter generations; (ii) within and between genders; (iii) intra and inter countries (especially among DCs, Emerging Powers, LDCs); (iv) within and between local economic systems; (v) within and between employment categories (e.g., unions, professional associations); (vi) within and between social groups (e.g., economic, ethnic, religious groups);

Indeed, we have to recognize, and the more so in the midst of a global crisis, that: (i) income inequality represents only one of the several dimensions of economic inequality; (ii) economic inequality may be determined by non economic inequality and generate further economic and non economic inequality ${ }^{7}$; (iii) also non economic inequality generates very important negative material and immaterial effects. All this makes less simple to find easy compensations to the economic and non economic costs of inequality.

What's more, the global crisis in action is showing us that even basic elements we used to regard as engines for equality in opportunities ${ }^{8}$ can be easily transformed over time into "privileges" by the

\footnotetext{
${ }^{7}$ For instance, a decrease in the incentive to invest in physical and human capital and an increase in social tensions and political instability may be driven by severe income equality.

${ }^{8}$ For instance, the citizens right to a decent life, a decent work, education and access to information and knowledge; or the refugee's right to be protected against refoulement.
} 
adverse circumstances. This leads to blurring the boundaries, which are shaped by economic, social and institutional behaviours and constraints, between what we could define a sustainable or unsustainable threshold of inequality. This can undermine the trade off between the bad and the good side of inequality.

The overall scenario could change and, according to some authors ${ }^{9}$, the XXI Century could be characterized by the prevalence of the "patrimonial capitalism" pre-existing in XIX Century. ${ }^{10}$ Since nowadays "Many people believe that modern growth naturally favours labour over inheritance and competence over birth" and "... democratic modernity is founded on the belief that inequalities based on individual talent and effort are more justified than other inequalities" (Piketty, 2014, p. 237 and p. 241), this shock could bring about a dramatic change in this popular confidence and consequent expectations. ${ }^{11}$

All this amounts to say that the very conception of inequality and its role in society is changing both in developed and developing countries and this change is strictly linked to its multidimensional character. $^{12}$

Therefore more than a single prescription derived from a mono-disciplinary perspective what is really crucial is the methodological assumption which is implied in the reconstruction of the nature, determinants and effects of inequality.

The assumption should comprise four steps. In the first step, a multi-disciplinary approach is important because it allows to understand more of the different dimensions of social and economic problems, avoiding, in this way, the pitfalls arising from the adoption of a unilateral perspective. Secondly, the focus on the conditions of different countries at the world level (developed, developing, Emerging Powers) is also essential because, apart from helping to grasp the different specific perspectives, allows to understand interactions.

In the third step, after the focalization on key research questions and real problems, each discipline $^{13}$ can perform his proper task, making use of its specific tools of analysis.

In the fourth and last step, multi-disciplinarity recovers a central role when we need to concentrate on policy design.

The capability to pursue such an approach is decisive in order to reach original goals in the framework of the integrated cooperation programme we are implementing with the Global Study Programme.

After the introduction, in paragraphs 2. and 3. we try to outline the rational for our theoretical analysis, underlining two main aspects. First of all, in paragraph 2 . we recall the reasons which makes inequality a multidimensional phenomenon, while in paragraph 3 . we explore the reasons why the models of capitalism theory $(\mathrm{MCT})^{14}$ is relevant for studying multidimensional inequality.

In paragraph 4. we try to outline the rational for our empirical analysis, applying the notion of institutional complementarity and examining the relationship between institutional complementarity, models of capitalism and inequality. Besides, refining Amable's analysis (2003), we provide empirical evidence on the relationship between inequality in income distribution and models of capitalism.

\footnotetext{
${ }^{9}$ The most prominent is Piketty (2014).

${ }^{10}$ In this respect the XX Century could have been the exception.

${ }^{11}$ This perspective of study can be relevant also in trying to assess the effects of other global phenomena taking place in the present historical phase, such as "land grabbing".

${ }^{12}$ This means that the definition of inequality cannot be only economic and that it crucially depends among other factors on the actual performance of the social system in which human beings live and interact.

${ }^{13}$ In our case, economics, sociology and law.

${ }^{14}$ After some early work by Albert (1991) and Prodi (1991), non-mainstream economists like Amable (2000, 2003) and Aoki (2001), as well as sociologists like Crouch $(2009,2010)$, have developed a theoretical framework based on the notion of variety in models of capitalism, we will refer to as MCT.
} 
In paragraph 5. we give some hints about issues in search for a new interpretation capable to fasten together the process of increasing inequality, the notion of symbolic violence and the MCT.

In the last paragraph we focus on conclusions useful for carrying on our research agenda.

\section{In what respects inequality is multidimensional?}

Inequality, both at the macro-economic level, which refers to national and supra-national entities, at the meso-economic level, which refers to local communities, and at the micro-economic level, which refers to individuals and generations, is in its essence a multidimensional and cumulative phenomenon.

Even when we split income inequality, which depends on the personal and functional distribution of income and wealth, from other sorts of inequality ${ }^{15}$ this phenomenon remains multidimensional, meaning that it evokes different types of individual and social background leading to the final outcome. One of the most important reasons is that inequality depends on wealth and income distribution and that "in all societies, income inequality can be decomposed into three terms: inequality in income from labour; inequality in the ownership of capital and the income to which it gives rise; and the interaction between the two terms" (Piketty, 2014, p.238).

The relevance of ownership of capital and inheritance, which is strongly linked to the historical tradition, contributes to link economic inequality to the socio-institutional framework and the sociocultural perspective. Talent and effort in this case are less important than inheritance and marriage in determining success and this in turns implies different tastes and behaviours. ${ }^{16}$

Just when we confine our research on inequality in income from labour, we have to be conscious that it can be derived from self-employment or wage labour, which imply totally different socioeconomic conditions, in which also the provisional or permanent character of employment contribute to differentiate the socio-economic background.

Furthermore, economic inequality is critical, but, the more we explore the extremes of the distribution, the more we note an overlapping and a bumping up of different dimensions of inequality. Low per capita incomes are highly correlated with low quality of life, and therefore with variables like poor health, low education, higher uncertainty and insecurity of employment and low participation to civil society. Therefore, countries with low human development index (HDI) suffer most because they tend to have greater inequality in more dimensions (UNDP, 2013).

Besides, following Marmot $^{17}$ (2013), we can distinguish between the material deprivation, which entails malnutrition, exposition to infected organisms, low resistance to their effects, exposition to hot and cold weather and to toxic elements, and the processes conditioning adult mortality, which take place even when poverty thresholds are overtaken. In this case human capital and human development are affected by the living situation of the single person both in terms of their direct outcomes (life expectancy, productivity, income) and in terms of impact on their creation and destruction channels (education, healthcare).

Another important implication is that a potential reduction in one dimension of inequality does not

\footnotetext{
${ }^{15}$ This practice has been favoured by the hegemony acquired by the neoclassical theoretical agenda in modern labour economics (Teixeira, 2003). This agenda, by the way, has greatly contributed to stress the mono-dimensional character of inequality with the human capital theory.

${ }^{16}$ Also illegal accumulation of wealth and post-conflict transition phases can have some impact, in this respect.

${ }^{17}$ This epidemiologist is laying the foundations of what can be defined social epidemiology, through the establishment of a systematic link between variance in health and life expectancy, on the one side, and social status, on the other.
} 
imply an even reduction in all its dimensions. ${ }^{18}$

The multidimensionality issue becomes more and more important as the awareness of the constraints caused by the existence of a "maximum sustainable inequality threshold" (MSIT) for the economy increases. ${ }^{19}$

But, in order to pursue our argument in a more systematic way, it is convenient to investigate the different dimensions of inequality singling out its basic characteristics, its determinants and its effects.

\subsection{Nature}

In the last quarter of a century a deep rethinking on the notion of well-being is leading to a rising agreement on the idea that it arises "from a combination of what a person has, what a person can do with what they have, and how they think about what they have and can do" (IDS, 2009).

Along this line of reasoning, well-being embraces three basic components: (a) the material and economic one, stressing welfare conditions, standards of living and economic values; (b) the relational one, emphasizing personal and social relations; (c) the subjective one, highlighting, moral values and perceptions, side by side with option and existence values. The three components are merged together and their boundaries are highly fuzzy (McGregor, 2007; Sumner and Mallett, 2013).

This, in turn, has induced a multi-layered revision of the notion of inequality, thanks to which nowadays also experience and intuition suggest that inequality is a multidimensional phenomenon: so many are its features and the circumstances in which it can be felt, conditional on culture, gender, ethnicity, religion, race, geographic location, age and other characteristics, relevant for human well-being, both across individuals and across groups.

It is important to specify that the multidimensional nature of inequality concerns both each basic component per se and the connections between the three of them. We mean that, even separating the material and economic dimension from the others, and limiting ourselves to consider inequalities in each of the proxies for the standards of living, since this can concern variables such as income, wealth, education, health and nutrition, the multidimensional nature of inequality leaks out. Of course the multidimensionality becomes broader if the three basic components are allowed to interact.

Among the non-economic components an essential role is played by ethnicity, gender and religion. In any case, beneath them, the access to many wants is often unevenly distributed and limited by economic constraints. Limiting ourselves only to very immediate examples, we could mention the option to use ${ }^{20}$ sophisticated drugs and cures, safe transports, qualified information and knowledge, natural and environmental resources of higher purity, and also a safe neighbourhood in which to rise children. Direct and indirect linkages connect material and immaterial components of inequality. Income constraints can easily bring about fragilities and drive persons to suffer from non-economic dimensions of inequality.

The inequality in access to goods and resources and the limits to an inclusive growth process are often augmented by complementarities among goods and the increasing relevance of "network products" $" 21$ which characterize the actual conditions of consumption.

Moreover, the increasing diffusion of non private goods, contrary to what could be envisaged, can contribute to increase inequality and decrease inclusiveness. It depends on the multiplicity of

\footnotetext{
${ }^{18}$ Even if this result is partly due to the measures used, a study by UNDP (2013) shows that in the last two decades at a worldwide level there have been much greater reductions in inequality in health and education than in income.

${ }^{19}$ We can define MSIT as the maximum level of inequality not inhibiting inclusive growth in a given economic system (Antonelli, 2013).

${ }^{20}$ Or even the benefit of knowing that a chance of utilization exists in the future.

${ }^{21}$ For a comprehensive study see Shy (2001).
} 
economic goods and the prevailing regulation structure for their provision. ${ }^{22}$

In both cases the quality of consumption is conditioned by the ease of use of related conditions and externalities.

\subsection{Determinants}

When we come to consider the determinants of inequality we can easily realize how much the social and genetic components are able to influence the economic ones and conversely. Wealth, education, and social privilege are strongly interrelated with psychological temper and genetic privilege.

At the personal and family level, a poor environment and natural gifts tend to lower the probability of economic success and to increase income inequality over the lifecycle. In fact, today, the majority of experts believe that behaviour and development are influenced by both "nature" and "nurture" 23 , while a minority take the extreme nativist or extreme empiricist views. However, researchers and experts still debate the degree to which biology and environment influence behaviour and performance. This suggest that the capability to take into account the interactions between the different dimensions of inequality is crucial.

At the nationwide and, especially, at the meso-economic level, the welfare infrastructure and public policies can be very important in supplying concrete and timely assistance to disadvantaged individuals and families in local communities. To the extent that microeconomic studies observe critical and sensitive periods in the life cycle of individuals, indicating, for instance, that some skills are more easily acquired during certain stages, for most configurations of disadvantage it is important to socially invest relatively more in the early stages of childhood than in later stages (Cunha, Heckman and Schennach, 2010). ${ }^{24}$ Education, health care and social welfare services at the local level are therefore important drivers of the capability of a community to practice cohesion and civic virtues, with significant effects on the distribution of labour market performance and labour income opportunities.

In this respect Adelman (2000, p. 18) adds another vital remark which is more appropriate in a meso-economic framework. "Cultural factors play a significant role in shaping institutions and societal responses to new challenges and opportunities. ... Both individualistic and communitarian cultures have advantages and disadvantages. ... Individualistic responses foster innovation, dynamism, creative destruction and geographic and social inequality. ... Communitarian responses foster social cohesion and the social ability to absorb change, and hence national resilience and malleability. They place a premium on social equity in growth outcomes and foster societal and governmental approaches to development. They also enable societies to more easily absorb short run decreases in personal welfare in the interest of the common long run good (Rodrik 1997, 1998)."

At the macroeconomic level, up to now the optimistic prediction by Kuznets (1955) was able to persuade the majority of the economic profession. Kuznets, using only U.S. data for the period 1913-1948, suggested that in every country, over the course of industrialization and economic development, inequality follows a bell-shaped curve. In this theory inequality plays the role of an endogenous variable which is decreasing after a certain mean income threshold has been overtaken. In contrast with this view, Adelman (2000, pp. 14-18) stresses that fifty years of development history show how inequality can play the role of an exogenous variable which is negatively correlated with economic development. In these cases the relationship is reversed. ${ }^{25}$

More recently, Piketty (2014, p. 15) adds that "... the magical Kuznets curve theory was formulated in large part for the wrong reasons, and its empirical underpinnings were extremely fragile. The

\footnotetext{
${ }^{22}$ For more details see Antonelli (2011).

${ }^{23}$ Even if the two terms are rephrased more exactly.

${ }^{24}$ For instance, the capability to timely support drug addicted young woman in the first years of age of their children can make social assistance much more effective in terms of inequality outcomes.

${ }^{25}$ Adelman (2000, p. 17) answers: "Is there a Kuznetz curve?" And her answer is "Not in the sense that a U-shaped course of inequality is inevitable.”
} 
sharp reduction in income inequality that we observe in almost all the rich countries between 1914 and 1945, was due above all to the world wars and the violent economic and political shocks they entailed (especially for people with large fortunes). It had little to do with the tranquil process of intersectoral mobility described by Kuznets."

This dispute is of crucial importance in studying inequality, and, at least judging from the last evidence which has been made available, the final outcome can be very influential in stressing that the multidisciplinary focus on the issue and its multidimensional character are essential ingredients of scientific research.

Another very controversial macroeconomic issue concerns the impact of trade liberalization on inequality.

In the mainstream view, trade openness, monetary and fiscal policy, financial development and the rule of law are the more relevant determinants in explaining cross-country variation in growth rates. Under the assumption that growth is a process distribution neutral, the study of the impact of economic policies on within-country inequality can be split into two distinct phases: first, the main policies able to maximize the growth rate are identified; second, $\operatorname{sign}^{26}$ and absolute value of the elasticity of inequality or poverty with respect to growth can be estimated. (Berloffa and Segnana, 2006, pp. 374-5).

The second phase is relevant not only for evaluating the impact of growth policies on inequality and poverty, but especially in order to assess the sustainability of growth in the long run. Moreover, the key role played in the growth process by the legal structure, and particularly by the security of property rights and privatization, apart from allowing us to stress how composite is the nature of the determinants of growth and inequality even in the mainstream approach, is relevant also in order to assess the transferability of economic and institutional models in development, transition and reconstruction processes.

However, empirical evidence shows that the growth process can be "highly distributionally nonneutral", as it has been argued by Kanbur and Lustig (1999, p. 8) and we shall see in paragraphs 2.3. and 4.

Furthermore, country specific conditions, which under appropriate circumstances may be ascribed to different models of capitalism, can make clear why the impact of the same policies is very different in terms of economic development and distribution of income and wealth or poverty. "Trade and accumulation policies are important in determining the spread-effects of growth and how growth and inequality interact. .... export-oriented growth in labor-intensive, consumer goods industries is equalizing because it raises employment and returns to labor unless specific policies are instituted to foster low wages. Also, when export-oriented growth is accompanied by low tariffs and low exchange rates, it turns agricultural terms of trade in favor of farmers and lowers consumer goods prices, with favourable distributional consequences." (Adelman, 2000, p. 16)

Thirlwall (2013, p. 4) extends the investigation range also to between-countries inequality and concludes that: "... trade liberalisation almost certainly worsened the distribution of income between rich and poor countries, and between unskilled wage-earners and other workers within countries, contrary to the predictions of orthodox theory." If the global scenario is only approximately similar to the one drafted in his recent book by Piketty (2014), this causal factor of inequality has to be taken seriously into account.

Finally, vicious circles fostered by austerity $\operatorname{traps}^{27}$ can also arise which negatively impact on inequality. "... adjustment patterns to the debt crisis of the 1980s have varied significantly among countries (Balassa 1989). Some developing countries, mostly in Latin America and Africa, adopted restrictive import regimes, deflationary government expenditure and macroeconomic policies, and restraining wage policies, reduced subsidies, and liberalized their domestic markets to reduce their

\footnotetext{
${ }^{26}$ Which, coherently with the Kuznets curve, is assumed to be positive.

${ }^{27}$ In this case, as also the recent evidence on European Union shows, countries that most ruthlessly cut their budgets see their overall debt loads increase as a share of the economy.
} 
current account deficits, lower inflation, and increase competitiveness. For the countries that followed this path, this was a lost development decade, with substantial increases in poverty, inequality and characterized by low- growth, from which these countries have started to emerge only in the 1990s." (Adelman, 2000, p. 8) The recent evolution of the most fragile European economies belonging to the EU can be interpreted along this line of thought.

\subsection{Effects}

Having so far stressed how much both basic characteristics and determinants of inequality are multidimensional, we cannot be surprised by the fact that also the effects of inequality share the same character.

The relationship between inequality and growth or development has been examined, especially at the macro-economic level, by a number of authors proving that high initial levels of the former ${ }^{28}$ may be harmful to the second, in this way discarding the assumption that growth is a process distribution neutral. ${ }^{29}$

Irma Adelman (2000) tried to single out the eight main lessons on the process of economic development experienced in half a century by developing countries, which has been understood as both multidimensional and highly nonlinear. In her view "The distribution of income is established mainly through the primary distribution of income that is generated by the production-determined circular flow" (p. 14) Moreover, "There is scope for choice in institutions, policies and in their sequencing, even at similar levels of development. The choices made, in turn, generate the initial conditions for subsequent development" (p. 6). Therefore, stages of development matter and different case studies, mostly East $\mathrm{Asian}^{30}$, suggest that equalitarian policies, pointing at the redistribution of the property of original factors of production (like land or education and human capital), led some countries to travel "the whole path from underdeveloped to developed, since the end of World War Two" (p.1).

In general, looking at the overall picture in developed countries, we are led to take into account two equally relevant sides of the story. On the one hand, inequality and polarization of earnings ${ }^{31}$ can have strong negative impact on several crucial spheres of the economic systems, such as contractual disputes, social instability and transaction costs ${ }^{32}$. Even the solidity of a stable relationship between the different generations, which favour their cooperation to common goals, can be jeopardized, making more complex to reach agreements at the individual and collective level. Furthermore, inequality can be considered a concurrent cause of decline in the middle-class prominence, which is currently destabilizing the economic and social setting in different countries.

On the other, inequality in performance and outcomes, can be regarded as a ordinary result of competition in everyday life, not conflicting with a sustainable growth. Therefore, in order to discriminate between physiologic and pathologic inequality and to assess to what extent this trade off risks to be unbalanced, an order of magnitude has to be ascertained. This is why it is appropriate to ask ourselves if does it exist and how can be measured what we could call MSIT for an

\footnotetext{
${ }^{28}$ Highly correlated with phenomena like: rent-seeking, social tensions, political instability, a poor median voter, imperfect capital markets and a small share of gross national income to the middle class, all of which lead to lower investment, higher taxation and lower economic growth.

${ }^{29}$ For a comprehensive account see Berloffa and Segnana (2006).

${ }^{30}$ Other countries, especially in Africa, Middle East and also Latin America, embarked on different paths, leading to widening inequality.

31 According to scholars, like Autor and Katz (2010), a phenomenon of "employment polarization" is strongly characterizing developed countries.

${ }^{32}$ Because of the increase in uncertainty about the prevailing institutional rules and the decrease in openness to share information.
} 
economy. $^{33}$

Definition and measurement of this threshold are subject to two conditions. First, it should refer to a kind if inequality which violates equality in opportunities. Second, it should refer to a level of inequality which does not match with economic, social and environmental sustainability.

This issue has been tackled, mostly indirectly by economic theory, in many different ways, even without knowing exactly at what level MSIT is positioned and more than that, even without being able to measure it in a comprehensive way. However, to the extent that a credible solution exist for the governance of inequality in the actual functioning and sustainability of an economic system, this option can be sufficient. ${ }^{34}$

But this question cannot be worked around anymore when no credible solution exist. And the problem, unhappily, is that this is becoming more and more true. In fact even if for different reasons and with different severity, all the three main methods generally employed in the past for this purpose have been badly worsening their performance well before the end of the XX century. And when the main available gateways to the equity issue fail, this, by itself, makes more relevant to measure the actual value of MSIT.

\section{Why the models of capitalism theory is relevant for studying multidimensional inequality?}

Summing up the main conclusions reached in the previous paragraph, we may focus on three crucial aspects.

(a) The debate on the fundamentals of inequality, signals its multidimensional nature and recommends high attention to the fact that different concepts and measures of inequality that have been utilized generates different results. Even the most apparently straightforward ones tend to retain a multidimensional nature and to refer to different domains pertaining to the overall economic and social system.

(b) The dispute on the determinants of within-county inequality steer us to stress its multidimensional causes and to suggest that a non secondary role has been played by economic and institutional factors that are internal, area specific and local, together with the global and external ones. This implies that we have to take into account several forces interacting at the micro, meso and macro level in shaping the final achievement.

(c) The study of the effects of inequality, apart from drawing attention to its multidimensional impact, shows how crucial can be its initial level for subsequent development. At this layer the issue concerning the relevance and definition of a MSIT can be raised with significant implications for the sustainability and inclusiveness of economic growth.

\footnotetext{
${ }^{33}$ We can define MSIT as the maximum level of inequality not inhibiting growth in a given economic system.

${ }^{34}$ Three have been so far the main methods experienced in the XX century to curb inequality over the years. All these methods are based on long term processes. Underpinning efforts at reducing economic inequality in all three cases was a recognition that social equality through equal citizenship had to be created. This meant that equal citizenship was created across genders, religions, castes, ethnicities and regions through law. Countries and societies in which those efforts have been made may not have achieved social equality enshrined in law fully, but that is the official benchmark they have established for themselves. An leading role of middle classes was crucial to this purpose.

The more direct method has been focused on the redistribution of real assets. Therefore, land and educational reforms, nationalisation of industries and services where ways to create economic equity, not only in the socialist and communist countries, but also in the emerging capitalist ones.

The second method, prevalent in the capitalist societies, was based on the redistribution of income through progressive taxation. The "welfare state", by taxing the rich more and spending more in public goods aimed at creating a system of gradual, but sustained reduction in income inequality.

The third method was shifting the burden to assure equity in the distribution of personal incomes to the mechanism of "compensating differentials" through private investment in human capital. ${ }^{34}$

Even if for different reasons and with different severity these three methods where badly worsening their performance well before the end of the XX century. And when the available gateways to the inequality issue fail, this, by itself, makes more relevant to measure the actual value of MSIT.
} 
Following this way of reasoning, we are led to think that the way in which different economic and social systems are able to evolve in terms of wide-ranging development and, more specifically, in terms of income and wealth distribution paths, which in turn strongly influence inequality, depends on four main pillars:

(i) the baseline, that is the initial economic and institutional structure of each system;

(ii) the capacity of each system to cope with and adapt to "natural" drift;

(iii) the aptitude of each system to face and absorb global shocks;

(iv) the capacity of each system to react to private strategies and public policies.

On the whole, an appropriate theoretical framework for dealing with such complex phenomena requires the possibility to start from the analysis of the interrelated sub-systems from which overall outcomes derive.

The basic idea is that the institutional architecture of each economic system promotes the adoption of some specific activities of innovation, while penalizing some others, through the establishment of complementarities involving enterprises and networks, macroeconomic regulation and functioning of goods, services and inputs markets, labour markets and channels of human resources education and training. ${ }^{35}$ The approach based on the idea that different models of capitalism determine the existing incentive structure and compete with each other is theoretically grounded and linked to the observation of real economic facts. ${ }^{36}$ Tax rates, benefit systems and access to the welfare system in the different models of capitalism can be rather effective in determining their performance in terms of inequality. ${ }^{37}$

Varieties of capitalism are originated by variety in interrelated sub-systems, whose main domains are the product markets, the labour markets, the financial markets, social protection, education and innovation. The support of a model able to nourish such an effort at the theoretical level is as much important as the availability of multidimensional indicators at the empirical one. And the main aim of the present paper is to begin to calibrate both components of our theoretical framework. This will be the task of part II.

However, in what follows of part I we have to put forward two fundamental clarifications in order to avoid just as many fatal misunderstandings.

The MCT recognizes a fundamental role to institutional structure in explaining the evolution of economic systems, but, and this is the first warning, it cannot be confused with neo-institutionalism nor pan-institutionalism.

The neo-institutionalist literature in economics tends to emphasize the endogeneity of institutional rules, the limits of economic policy and the boundlessness of institutional reforms when aiming at improving the performance of national economies. ${ }^{38}$ In this way it tends to ignore the complexity of interactions which determine their performance and swamp into pan-institutionalism. As suggested by Schettkat (2003) and Zenezini (2006), best practices are considered key research questions and dominant prescriptions also in the realm of institutional architecture. ${ }^{39}$

\footnotetext{
${ }^{35}$ See also Antonelli (1997).

${ }^{36}$ Common features of this approach with the study of the German "social market economy" (in German, "Soziale Marktwirtschaft") can be found.

${ }^{37}$ For instance, according to different statistical sources, while economic inequality shows an increasing trend for English speaking countries, India and China, this is not true for continental European countries and Japan, nor for the Mediterranean and Scandinavian countries.

${ }^{38}$ While Douglas North (1990) seems open to a semi-endogenous explanation of institutions, Gary Becker (1993) is not.

${ }^{39}$ The conclusion is that institutional settings are probably relevant in terms of distributional effects, but scanty and not easily detectable in terms of overall efficiency and aggregate performance. The evidence presented in several empirical studies, according to Zenezini (2006), Freeman (2000) and Howell and Huebler (2001), does not support the theoretical approach endorsed by (IMF, 2003, p. 129) for which "the causes of high unemployment can be found in labor market institutions". By extension we could argue that not even the MCT is capable to directly explain the aggregate
} 
While in the literature on models of capitalism even if a model cannot be defined without institutions, because they shape and regulate the interactions between agents, institutions play the role of resources as well as constraints.

This difference can be better assessed if we consider that in the neo-institutionalist literature ${ }^{40}$ the economic structure interacting with the institutional one is straightforwardly based on the general equilibrium theory and the theoretical model is neutral with respect to the empirical setting. Therefore the step of empirical investigation becomes a purely descriptive application of this model, the rules derived from the best practices becomes universal and the "rule of law" is all over transferable.

This is not true for the literature on MCT. In this case, first of all, the institutional complexity is accommodated in the model through the notion of "interrelated sub-systems" and complementarities are not necessarily positive, leaving ground for failures. Moreover, this literature does not pretend to explain all kind of performance of economic systems, and, what is more important, it is based on a different theory of economic structure. Its main assumptions turn out to be the following:

(i) non optimality of the final configurations (no single best solution can be achieved);

(ii) diversity in micro, meso and macro objectives prevails;

(iii) redundance and resilience are considered as much important as effectiveness;

(iv) real economic interdependences are relevant for describing the economic structure;

(v) income distribution and inequality are not explained completely in an endogenous way.

In this manner institutional structure and economic structure are always interacting for at least three basic reasons. First, economic structure and institutional structure relate at the same level of abstraction and institutions cannot be interpreted simply as empirical artefacts or ad hoc elements relevant only when we come at the applied stage of research. Second, the behaviour of agents coherent with the economic assumptions is shaped by the action of "institutional entrepreneurs" (e.g., élites, policy makers at the different levels of government and governance) in the making of institution building. Third, scarcity of economic resources conditions very often the mandatory character of the institutional rules and fundamental rights are reshaped as law in books rather than law in action.

The search for complementarities or codetermination between institutional structure and economic structure becomes the core purpose of scientific research in an approach based on two methodological assumptions:

(a) institutional rules, legal codes and constitutions are necessary, but not sufficient conditions for cohesion and sustainability of economies and societies; ${ }^{41}$

(b) institutional rules, which are essentially varied and partial, derive from different value judgements associated with different cultures and specific historical backgrounds ${ }^{42}$.

The second warning is tantamount crucial since it makes clear that focusing on interrelated subsystems does not amount to believe that mechanical and deterministic forces dominates the interactions. Apart from the relevance of the stochastic components, the multiplicity of potential

performance of labour markets as a residual outcome of a logical sequence in which labour markets comes last. However, the latter can explain distribution and inequality effects to the extent that a certain degree of exogeneity in one of the distributional shares is assumed.

${ }^{40}$ Reference could be made to the economics of discrimination by Becker (1957).

${ }^{41}$ For instance, if a person get sick up against famine or child labour and fights in favour of a "decent work agenda", this is not because it exists a law prohibiting them, but for ethical reasons that hopefully are the precondition for new institutional rules.

${ }^{42}$ E.g., even within EU variety is binding. Dignity, freedoms, equality, solidarity, citizens' rights, and justice are the titles included in The Charter of Fundamental Rights of the EU (2010). However, the Charter's provisions do not extend to the competences as defined in the EU Treaties and the EU cannot intervene in fundamental rights issues in areas over which it has no competence. 
outcomes does not allows us to enfold in few and arbitrary categories the set of final configurations taken by each economic system. This statement can be better understood if we focus on the meaning of complementarity and match it with an applied example.

The notion of complementarity is manifold and, contrary to what may be thought, its most appropriate meaning in MCT refers to the occurrence of mutually compensating components rather than of reciprocally reinforcing components or similarities. ${ }^{43}$ Therefore, to the extent that balancing characteristics in one way or another are better describing institutional complementarities in MCT, determinism is prevented to exercise a significant role in it.

The example refers to the balanced complementarity taking place in these months between the channelling of a relevant amount of households savings in Germany towards internal financial investments with very low return ${ }^{44}$ and the pro-deflation policy pursued by Bundesbank. If inflation goes up in order to comply with the pro-growth policy, which is complementary to the needs of Southern Europe countries, this will damage the purchasing power of German households that where led to choose these kinds of financial investments thorough the path dependence generated in the German financial system in the earlier phases of the global crises. This example shows how even in the case of the variously revered German model complementarities are not always the result of convergence of best practice institutions. Moreover in the next paragraph we shall see how this can have a negative impact on other member countries of EU.

The ever-changing taxonomies arranged for describing the different models of capitalism can be interpreted as provisional outcomes of a theory in search of more comprehensive models and of greater ability to work out this challenge. The taxonomy can change in each given point of time and overtime because models of capitalism can evolve through the transformation of complementarities.

\section{Rationale for empirical analysis}

\subsection{Institutional complementarity as a tool of analysis}

The notion of institutional complementarity plays a pivotal role in both the analysis of varieties of capitalism and, more in general, in the analysis of the role of institutions. The latter point seems to be quite obvious, but it is not. In these last thirty years standard neoclassical economics has worked out a lot of models which incorporate the existence and the working of institutions and their influence of economic performance. Basically, in these last thirty years the great bulk of neoclassical labour economics can be interpreted as the development of models which deviate from the standard model of perfect competition due to the existence and operation of a specific institution, giving rise to a sub-optimal equilibrium. If one considers the debate on labour market flexibility in European economies it seems quite difficult to deny this statement; most of standard approaches used to explain involuntary unemployment as the consequence of specific institutional settings, which prevent the labour market from adjusting with respect to unbalance between labour demand and supply. ${ }^{45}$ The analysis of the effects of the functioning of a single institution, regardless of how this institution interacts with other institutions, is a consequence of the methodological approach of standard microeconomics, in which the analysis focuses on the direct effects of the single institution, neglecting the complementarity relationships that the institution establishes with

\footnotetext{
${ }^{43}$ As suggested by Crouch, Streeck, Boyer, Amable, Hall and Jackson (2005, pp. 359-363), these two notions coexist with the notion employed in the economic theory of consumption for distinguishing between substitute and complementary goods and with the general notion of similarity. The first one shares with that focusing on mutually compensating components the notion of completion through compensation.

${ }^{44}$ In 2012, according to Eurostat data, $80 \%$ of the 4,700 billion euro savings where invested in deposit accounts, retirement accounts and bonds with negligible returns.

${ }^{45}$ One could develop this paragraph talking about theories of real wage rigidity, such as the efficiency wage hypothesis or the insider-outsider model.
} 
other institutions ${ }^{46}$.

However recent developments in the field of institutionalist analysis have focused on the interaction between two or more institutions and has led to introduce the notion of institutional complementarity. We can have institutional complementarity when two or more institutions interact so that the working and the performance of the institutions involved in this relationship is affected by the working and the operation of the others. ${ }^{47}$ Basically, the operation of a single institution reinforces and is reinforced by the functioning of other institutions.

Even on the basis of the functionalist interpretation of institutional complementarity, there are two important consequences of institutional complementarity: (ii) possible prevailing of sub-optimal configurations of institutions and (ii) path dependence.

(i) Aoki shows that when two institutions are complementary this configuration can be stable even though, if compared to another configuration of complementary institutions, it results to be suboptimal.

(ii) the existence of complementary relationships can cause institutional lock-in and path dependence. Applying the notion of path dependency developed in the field of evolutionary economics by Arthur (1994) and David (1994), Kang (2006) shows how institutional complementarity can bring about path dependency since it implies four mechanisms which are at the basis of path dependency: (a) large set-up costs or initial costs for the agents affected by the operation of the institutions; (b) learning effects; (c) coordination effects; (d) adaptive expectations. This entails the absence of a single best institutional combination.

In this framework it is very important to understand, first of all, who are the institutional builders. ${ }^{48}$ Following Streeck (Crouch, Streeck, Boyer, Amable, Hall and Jackson, 2005), the political élites acts as founders of specific institutions. It is very important to identify the composition of these élites and the mechanisms through which these élites contribute to the process of institutional building. Second, we need to know who are the agents whose action is affected by the operation of institutions. For some agents the institution can be considered as a set of constraints and rules of the game (à la North), for others institutions can be resources. It is very important to understand the objective functions of these agents. Third, we need to understand how the operation of complementary relationships can be influenced by exogenous factors. At this point, in neoclassical economic theory one would try to define the objective function to maximise subject to a specific resource constraint. Sticking to this approach, one can say that the institutional entrepreneurs would set up institutions in order to take the maximum feasible advantage from the foundation of the institution itself.

Using a more general language, it is important to understand which "ex-ante" purpose the institution pursues. Basically, that means that it is important to understand why a specific institution has been set up and its dynamics. However, it is important to emphasise that, unless we assume the existence of a "homo economicus", gifted with unlimited capability to work out the outcomes of her/his actions and choices, the effects of a process of institutional building may well differ "expost" from what the institution was "ex-ante" designed for. This is a consequence of the complementary relationships which can be established among a bundle of institutions; the setting up of a specific institution affects the sub-system for which it has been conceived and, through the

\footnotetext{
46 For example, as to the effects of the laws concerning the firing restrictions, the standard approach focuses on the capabilities of firms to adjust the level of employment in order to reach the optimal equilibrium. This analysis rules out the effects, of this legislation on the propensity of firms to provide training for their employees, emphasised by Soskice and Hall (2001). This side of the analysis can be caught only if one takes into account the complementary relationship among institutions. In the standard microeconomic neoclassical approach, institutions are conceived as deviation with respect to an institution-free equilibrium.

${ }^{47}$ See Aoki (2001) for a formal definition using a game theoretical approach.

${ }^{48}$ Or the "institutional entrepreneurs".
} 
complementary relationships established with other institutions, it can affect other sub-systems. ${ }^{49}$ In the process of institutional building, different institutional entrepreneurs, with possible contrasting objective functions, can be involved either in the setting up of the same institution or in the assembly of interacting institutions. This process follows a trial and error procedure pursued by agents with limited rationality, in a highly uncertain environment. As a result, institutions do not necessarily establish optimal relationships and, actually, can hinder each other. Even though they are neglected in the literature, in this respect we can refer to the establishment of "negative complementary relationship". However, the alleged negativity/positivity of a set of institutional complementary relationships depends on the objective functions of both individual agents and the whole social system. For example, let us consider a certain framework of institutional complementarity promoting the compression of the relative wage structure. Can we deem this effect satisfactory, neutral or negative? We cannot reach a definite answer.

\subsection{Complementarity and models of capitalism}

A model of capitalism is a cobweb of complementary institutions which affect the performance of a socio-economic system, based on capitalistic relationships among agents. This definition is consistent with Amable's approach who maintains that "a variety of institutional complementarities is possible, generating a diversity of models of capitalism (Amable, 2003, pp. 102).

Amable points out five different types of institutional domains: (a) product markets; (b) labour markets; (c) financial system; (d) social protection system; (e) educational system.

As institutions affect the distribution of income among wages, profits and rents through the structuring of both the labour markets and the markets for goods, services and productive factors, the model of capitalism defines the distribution of income. Starting from this point of departure, we can state that different models of capitalism should exhibit different level of inequality in income distribution. From this, following the Bourdieu's framework of analysis, inequality in access to education, health services arise. It is important to stress that the definition of a model of capitalism is based on the operation of a set of institutions and does not imply an interpretation about the functional relationships among economic variables which define an economic model. Of course, this does not mean that the model of capitalism is neutral as to the relationships among economic variables, but simply that the model of capitalism is defined regardless of any economic model.

We could mention institutional change as a consequence of change in the environment, in the agents affected, in the operation of the institution and/or in their objective functions. Contrary to Amable's statement that "institutional forms $\mathrm{x}$ and $\mathrm{y}$ are compatible if their coexistence does not set in motion a process of institutional change, in the sense that some political forces would like to keep $\mathrm{x}$ and change $y$ ", when there are negative complementary relationships we might observe the start of an institutional change only if one of the institutional entrepreneurs prevails on the others or if the institutional entrepreneurs reach an agreement for a change.

As institutions are linked together by complementary relationships, then the effects of institutional building can be properly appraised only taking into account the cobweb of complementary relationships which can be potentially activated with the introduction of a new institution. An institution is not efficient only "per se" but also in accordance with the relationships established with the operation of other institutions. ${ }^{50}$ In any case, important questions remain open: can we analyse the effect of structural adjustments prescriptions enforced by IMF through the perspective of institutional complementarity? can we interpret the failures and, especially, the negative side

\footnotetext{
${ }^{49}$ The example can be made of labour laws regulating hiring and firing and propensity of firms to provide training for their employees.

${ }^{50}$ In paragraph 5. we will try to develop some ideas concerning the EU evolution.
} 
effects of these policy through the lens of institutional complementarity?

\subsection{The empirical analysis}

\subsubsection{The research targets}

After discussing the pivotal role played by the institutional complementarities in the definition of the models of capitalism, we have to test the empirical relevance of this analysis. The analysis proceeds along two different stages.

First of all, we have to verify that by using a set of indicators of the operation of institutions and their complex interactions, we can classify different countries into distinct groups, each one corresponding to a model of capitalism.

Secondly, assuming that the previous stage of empirical analysis is successful, we have to see if the classification introduced discriminates significantly the countries as far as income inequality is concerned.

Basically the research questions we are going to address through empirical analysis are the following:

(i) Is the approach followed by MCT, which defines models of capitalism on the basis of institutional complementarities, empirically robust?

(ii) Does income inequality depend on the model of capitalism or is it an inherent characteristic of capitalism itself with more or less similar thresholds everywhere? Of course, the question does not refer to the existence itself of income inequality in capitalistic societies, which one should take for granted, but to the degree of inequality in income distribution.

Empirical analysis is based on two distinct steps. The first step consists in an application of cluster analysis in order to identify empirically the models of capitalism. Once we have defined the various models of capitalism, we proceed to the second step in which we estimate the relationship between inequality and model of capitalism.

\subsubsection{Cluster analysis and models of capitalism}

First of all, we have refined Amable's (2003) classification of the five sub-systems ${ }^{51}$. He points out the five domains mentioned earlier and, given the relevance of technological change in labour market dynamics, we have decided to add a set of indicators concerning the degree of technological development of a country and the role played by both the private and the public sector in activities of R\&D.

Following (Everitt, Dunn, 2001, pp. 125) cluster analysis provides a "parsimonious way of describing the patterns of similarities and differences in the data". Basically, this means that through cluster analysis one can group different statistical units and classify them. However, as Everitt and Dunn state, we have to remember that "any classification is simply a division of the objects or individuals of interest into groups based on a set of rules - it is neither true or false (unlike, say, a theory) and should be judged largely on its usefulness" (ibidem, pp. 126).

Each cluster groups a set of countries which, on the basis of a series of statistical indicators, outlined in the Appendix, exhibits a high degree of homogeneity among them and a corresponding high degree of heterogeneity with the countries grouped in other clusters. More details on cluster analysis can be found in Appendix.

\footnotetext{
${ }^{51}$ He uses the term domains.
} 


\subsubsection{The data}

All the data used for the cluster analysis come from the OECD.StatExtract, the database set up by OECD and the World Development Indicators (WDI-WB), collected by the World Bank ${ }^{52}$.

For each institutional domain (Labour market, Product market, etc.) we try to recover data for each year in the time span between 1995 and 2010 for the maximum number of countries. The final set of indicators used in the analysis is the result of the process that try to minimise the loss of information on countries and, at the same time, to retain the maximum possible number of years. However, it was impossible to obtain complete time series for all the years between 1995-2010 for all indicators and all the countries. So we decided to implement the analysis at two specific point in time: at the beginning and at the end of the period (1995 and 2010). The definition and the source of indicators we used in the analysis is reported in Table A.1 in appendix

For the analysis of income inequality, we have used an estimate of Gini index (gini_net) of inequality in equivalized (square root scale) household disposable (post-tax, post-transfer) income, using Luxembourg Income Study (LIS) data as the standard. This datum comes from Standardized World Income Inequality Database (SWIID) provided by the university of Iowa.

Following Liskanen (2007), the LIS disposable income concept is given by gross income (GIW) minus mandatory contributions and income taxes. In terms of income variables, it can be expressed by means of the following equation:

\section{$L I S \_D P I=G I W-C O N T R I B-I N C T A X^{53}$}

As far as the selection of countries is concerned, the complexity and the richness of data required for the empirical research has forced us to focus the analysis on a selection of 24 OECD countries, which refer to: (a) 19 European countries - Austria, Belgium, France, Germany, Italy, Netherlands, Denmark, Finland, Norway, Sweden, Czech Republic, Poland, Portugal, Slovak Republic, Spain, Hungary, Ireland, Switzerland and United Kingdom; (b) 2 Asian countries - Japan and Korea; (c) 2 American countries - Canada and the United States; (d) 1 country from Oceania - Australia.

The composition of the sample of countries is strongly Eurocentric, despite it includes some important extra-European economies.

One of the most remarkable limits of this analysis is the exclusion of both developing countries and, especially, the so-called Emerging Powers (Brazil, Russia, India, China and South Africa). As a partial justification for this limitation, of which we are aware, we can say that data availability for these countries can be rather problematic.

\subsubsection{The cluster analysis}

In order to identify whether different models of capitalism exist, we apply the cluster analysis to the institutional indicators of the 24 countries for which we have data at 1995 and 2010. We select the maximum set of indicators common to both periods. Before applying the cluster analysis, we proceed to standardize the raw data in order to eliminate the influence of the different measurement units.

In Tables 1 and 2 the cluster composition in 1995 and 2010 is presented. The choice of the number of cluster in each year are based on the dendrograms shown in Figures 1 and 2, and the measures reported in Tables A.2 and A.3 in Appendix.

\footnotetext{
${ }^{52}$ See the Appendix for the list of statistical variables used and the source.

${ }^{53}$ Roughly speaking Gross Income can be defined as the flows of earnings of productive factors plus the pensions plus transfer income. For a precise definition see Niskanen (2007).
} 
Table 1. - Cluster composition - 1995

\begin{tabular}{|l|l|l|l|l|}
\hline 1 & 2 & 3 & 4 & 5 \\
\hline $\begin{array}{l}\text { Czech Republic, } \\
\text { Poland, Portugal, } \\
\text { Slovak Republic, } \\
\text { Spain, Hungary, } \\
\text { Ireland }\end{array}$ & $\begin{array}{l}\text { Denmark, } \\
\text { Finland, Norway, }\end{array}$ & $\begin{array}{l}\text { Austria, Belgium, } \\
\text { France, } \\
\text { Germany, Italy, } \\
\text { Netherlands }\end{array}$ & $\begin{array}{l}\text { Japan, } \\
\text { Switzerland, } \\
\text { Korea }\end{array}$ & $\begin{array}{l}\text { Australia, } \\
\text { Canada, United } \\
\text { Kingdom, United } \\
\text { States }\end{array}$ \\
\hline
\end{tabular}

Data source: our elaboration on OECD data 
Figure 1. - The dendrogram based on 1995 indicators

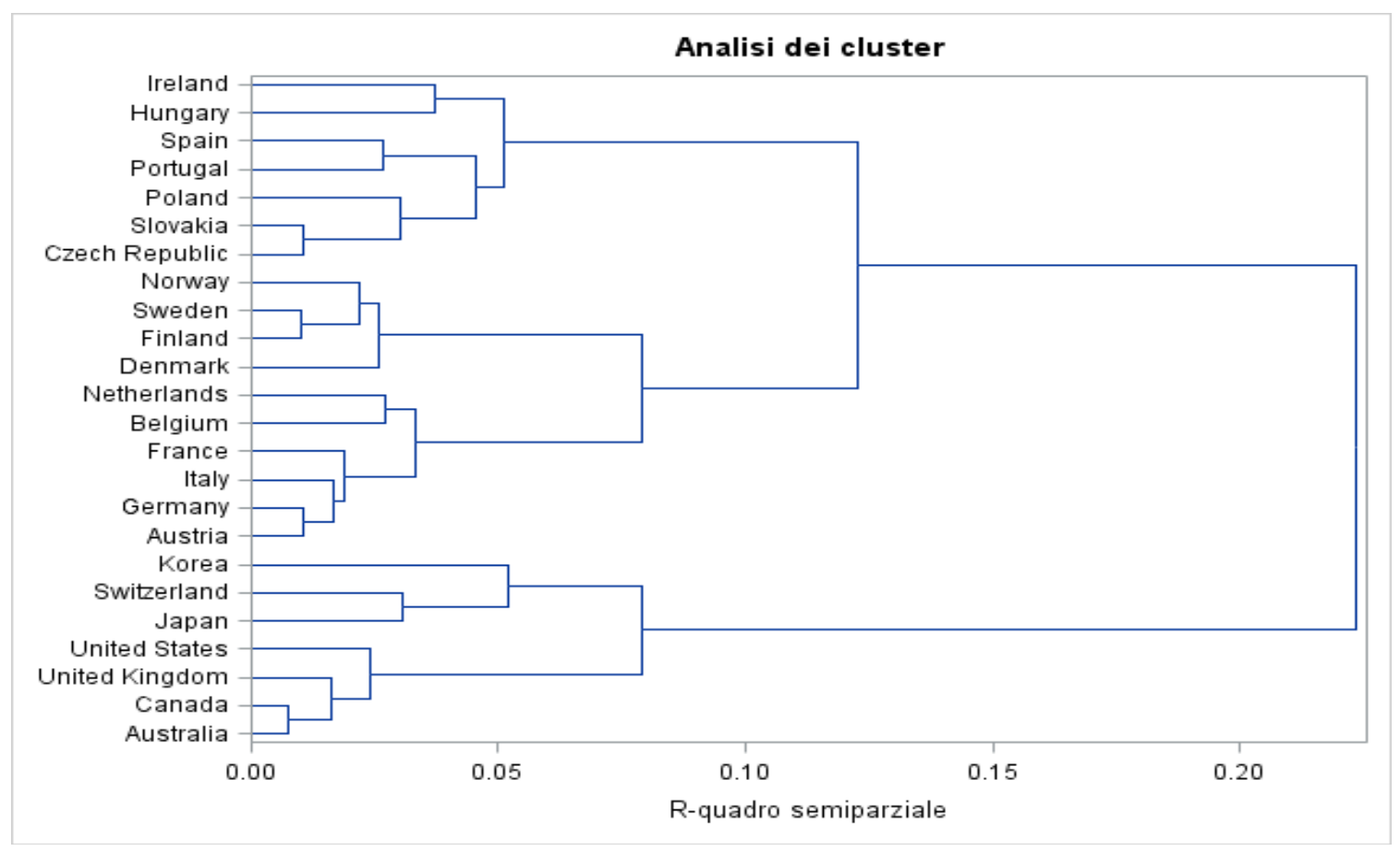

Table 2. - Cluster composition - 2010

\begin{tabular}{|l|l|l|l|l|l|}
\hline 1 & 2 & 3 & 4 & 5 & 6 \\
\hline Czech & France, & Denmark, & Austria, & Japan, Korea & Australia, \\
Republic, & Ireland, & Finland, & Belgium, & & Canada, \\
Poland, & Netherlands, & Norway, & Germany, & & United \\
Slovak & Portugal, & Sweden & Italy & & Kingdom, \\
Republic, & Spain & & & & United States, \\
Hungary & & & & & Switzerland \\
\hline
\end{tabular}

Data source: our elaboration on OECD data 
Figure 2. - The dendrogram based on 2010 indicators

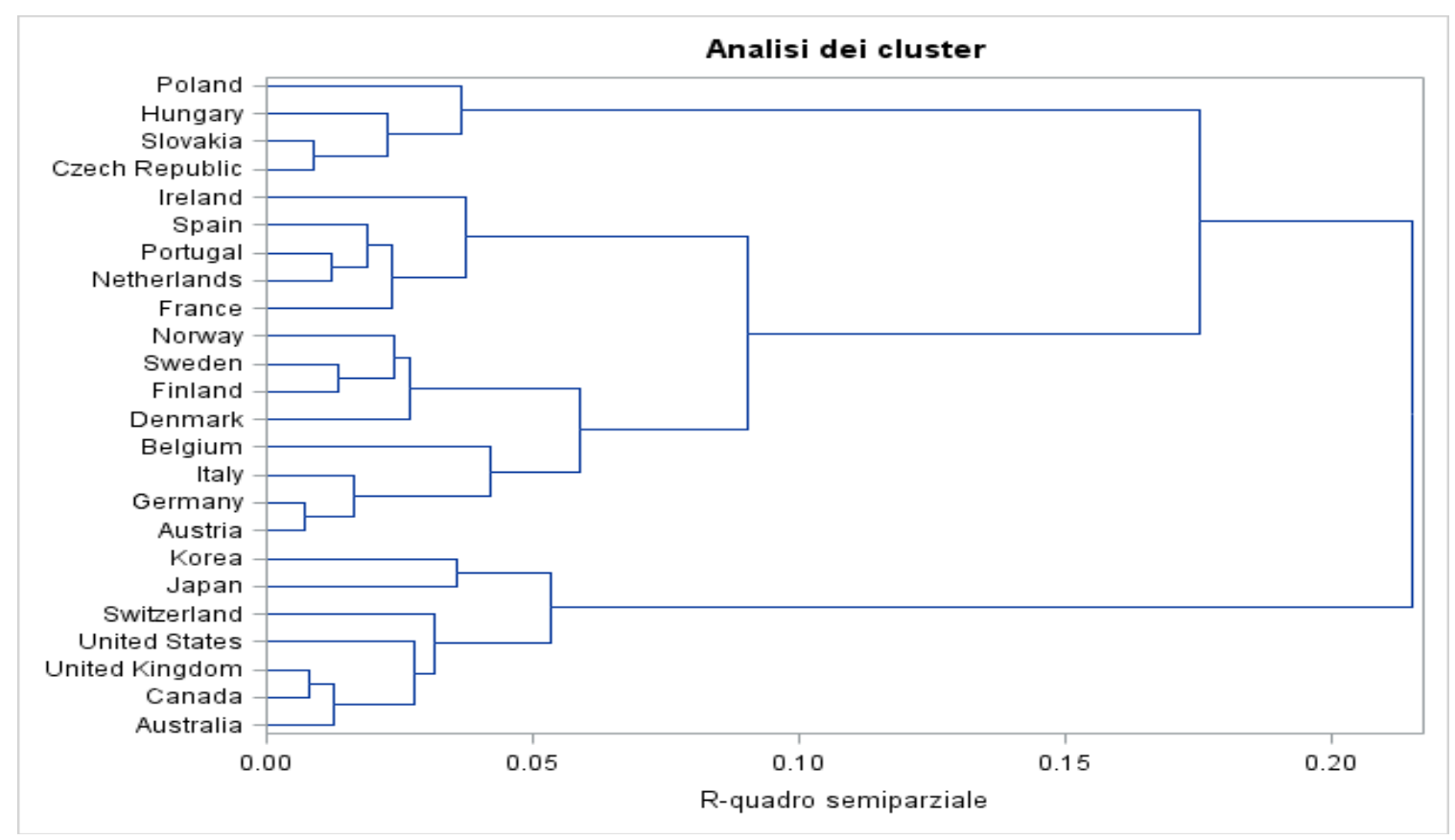

In the following we try to characterize the different groups found by the cluster analysis for each time period and compare the differences in the grouping and the characteristics across time. We start from the results of the cluster analysis for the year 1995, so we can compare our results to the grouping in Amable (2003) for the late ' 90.

Using data at 1995, two clusters are clearly identified as the ones that correspond to the two opposite models of capitalism identified by Amable (2000, 2003): the market-based capitalism model (or Anglo-Saxon economies) that corresponds to the cluster composed by USA, Canada, Australia and UK, and the Social-democratic model, which corresponds to the cluster composed by the Scandinavian countries (Finland, Norway, Denmark, and Sweden). In addition to those clusters, a cluster with Japan and Korea, associated by Amable to the Asian model, emerged in our analysis. However, in our analysis this cluster includes Switzerland, which in Amable's analysis can be found in a cluster with other continental European countries.

The main differences between our cluster analysis and Amable's one can be identified in the composition of both cluster 3 and cluster 1 .

Cluster 3 is associated to the model of Continental European Capitalism. Although the composition of the cluster in our and Amable's analysis is similar, there are a few exceptions. For example, in our analysis Norway is classified in the cluster that identify clearly the social-democratic model while Amable classifies this country together with France, Germany, Austria, Belgium and Netherlands (plus Switzerland and Ireland). Moreover, we have found that Italy is in a cluster with Germany and France, while Amable groups Italy with Spain, Portugal and Greece in a cluster collecting all the most Mediterranean countries. Finally, in our analysis one can observe the rising of a cluster (cluster 1) including Spain, Portugal and Ireland as well as four European countries from central and eastern Europe (former socialist-block countries) that were never considered in previous empirical analyses.

As already stressed by Amable (2003), even though the identification of clusters allows to group countries into homogeneous subsets, that does not mean that one cannot observe a certain degree of heterogeneity among countries of the same cluster, as far as certain variables are concerned. Therefore, each cluster identifies a specific Model of Capitalism, which can be considered as a sort 
of ideal-type, however countries belonging to the same cluster can significantly differ as to certain variables.

In describing the clusters we look at the cluster's average for each indicator (Table A.4.) and consider a measure of the level of heterogeneity between clusters and homogeneity across countries within clusters. This is based on the share of the between-cluster variability (deviance) of each indicator on total variability: it measures how much of the total variability depends on differences among clusters, and so it indicates the characteristics that mostly discriminate the clusters (Table A.5.).

Cluster 6 is characterized by a deregulated product market, since we can observe low values of the indicators of Product Market Regulation (PMR ) - State control, Barriers to entrepreneurship, and Barriers to trade and investments. As to labour market, in this cluster countries present low values of the Employment Protection indicators, little coordination or centralization for wage bargaining, and low value of trade union density. Interestingly, these countries have a sophisticated financial system, with high stock market capitalization on GDP, highly dispersed banking systems, significant presence of foreign banks and a relevant domestic credit on GDP. In this cluster social protection is poor and the welfare system is less developed; social public expenditure on GDP is quite small in comparison to the other clusters. The same can be said for unemployment benefit and the incidence of public expenditure on passive labour market policies. This group of countries exhibits high level of gross domestic expenditure in R\&D on GDP and a high number of researchers among employees. Finally, one can observe what happens to the indicators related to the working of the fiscal system. In this cluster both the level of taxation on GDP and the value of the tax wedge are lower than in other clusters (with the exception of cluster 4). This framework is confirmed by the structure of revenues by the different sources of taxation: taxes on income, profit etc. accounts for the $46 \%$ of total taxation, while the amount of social security contribution on total taxation accounts only for the $14 \%$.

At the other end of the range of clusters cluster 2, which includes the Scandinavian countries and Denmark. This cluster fits in with the social-democratic model of capitalism, characterized by a highly developed welfare system with the highest social public expenditures and high values of other welfare indicators (public expenditures on unemployment, public expenditure on passive and active labour market policies). Labour market is characterized by the highest participation in trade union and a high value of the indicator of coordination and centralization of wage bargaining, as well as a stringent employment regulation, even if not as strict as cluster 3 . This cluster also presents high values of the level of taxation The financial system is highly concentrated with a low presence of foreign bank. Besides, the system of Research and Development is quite competitive because this cluster presents one of highest value of Gross domestic expenditure in R\&D on GDP and the highest number of researchers on total employment.

Cluster 5, composed by Japan, Korea, and Switzerland, is close to the cluster 6 in many domains and it is the most distant from the social-democratic model. It is characterized by low level of social protection, low public social expenditures and a low level of taxation on GDP and on labour. The labour market is more regulated than the market-based model with a certain level of employment protection, especially for temporary employment, and a high level of coordination and centralization of wage bargaining but a very low participation in trade unions. It differentiates most from the market-based model regarding the product market regulation, with high levels of State control and different type of barriers. The financial system is well developed, with high value of all indicators concerning the stock market and limited banking concentration, but it differentiates for the major role of the bank system (the highest indicator of domestic credit provided by banks). It is also characterized by a R\&D system with high investment, provided especially by the private sector, and a high number of researchers on total employment.

The other two clusters are somewhere in between the two extremes and are similar in some respect. Cluster 3 groups the countries that in the Amable's analysis were associated to the continental European capitalisms, with some exception (Norway, Italy and Ireland). This cluster is characterised 
by a high level of employment protection (especially for temporary employment) coordination and centralization of wage bargaining and trade union density. In addition to that, one can observe a high level of social protection, especially of employment-based benefits. The product market is quite regulated, with higher level of state control and barriers to entrepreneurship compared to the others clusters. The level of taxation is very high, especially on the labour factor. Hence, in many aspects this cluster is close to the cluster of the Scandinavian countries. The difference lies in the domain of education and R\&D. In fact, both the level of public expenditures on education (\% of GDP) and the Gross domestic expenditure in R\&D on GDP are the lowest among all clusters. The same can be said as far as the number of researchers on total employees is concerned.

Cluster 1 is a novelty with respect to the analysis of Amable, due to the presence of some countries that were not previously available. We recognise a group of eastern European countries, and other three countries (Ireland, Portugal and Spain) that were classified differently in previous analyses. This cluster is close to cluster 3 with regard to many aspects. It has a strict employment protection (less for temporary contracts) and a comparatively low level of coordination and centralization of wage bargaining. Participation in trade unions is not so high as in the former cluster. In addition to that, countries in this cluster have a limited welfare state with a lower level of social protection than the previous cluster but higher than the "market-based" cluster. Product markets are strictly regulated and the financial system is characterized by a high concentration of the banking system and a small and not too much efficient stock market. The level of taxation is comparable to cluster 3 but the structure by type of taxation evidences a higher incidence of "indirect" taxation rather "direct taxation". Finally, one can observe both very low levels of investments in R\&D and in the number of employees working in R\&D activities.

However, the description hides the within-cluster heterogeneity across the countries because we compare the clusters' averages. Indeed, we find that while for some indicators the clusters are well differentiated and, to some extent, homogeneous inside, for others still remains high heterogeneity within clusters. This emerge from the data in Table A.5: differences between clusters are well accounted by a small number of indicators, for which the between-cluster deviance is greater than $65 \%$. For many indicators the within-cluster deviance is greater than $50 \%$ of the total deviance, indicating that there is a substantial heterogeneity within clusters.

The time lag between 1995 and 2010 is long enough to leave room for structural change and for radical institutional transformations to occur, which can shift one country from one model (cluster) to another one. Indeed, the situation at 2010 shows a greater diversification, above all for the European countries: now we can clearly distinguish a cluster of Eastern European countries (cluster 1) and a new cluster (cluster 2) is formed putting together some countries that were previously allocated to two different clusters. This may also be revealed by looking at the share of betweencluster deviance, that is higher than $65 \%$ for a greater number of indicators.

The clusters differentiate mostly on institutional indicators related to the labour market, the fiscal and financial system and the system of drivers of technological innovation. Looking at Table A.6, which shows the cluster mean of each indicator, we notice there are large differences in trade union density, with the highest value for the cluster that includes the North European countries (cluster 3) and the cluster with Austria, Germany, Italy, and Belgium (cluster 4), and the lowest values for the Asian countries (Japan and Korea - cluster 5) and the Eastern European countries (cluster 1). We observe a quite similar pattern for the degree of coordination of bargaining, with the exception of the cluster of Japan and Korea, which is closer to the cluster of North European countries.

There are also large differences in the incidence of labour taxation and the level of the statutory minimum wages. Tax wegde is wide especially for cluster 4 (Austria, Germany et al.), and the North European countries, as well as for Eastern European countries, while cluster 6 (Australia, Canada, UK, Switzerland, and USA) and cluster 5 has lower values of tax wedge than the former. Consistently with the previous pattern, these two clusters have the lowest values of minimum wage in comparison, for example, to cluster 1 or cluster 2 . The small value of this indicator for cluster 3 and 4 is due to the fact that in the majority of those countries there is no minimum wage. 
Taxation also varies greatly between clusters. Regarding the share of income, profits etc. taxes on total taxation, for two clusters (cluster 6 and 3) total taxation flows come largely from direct taxation while there is a better balance between different sources of State revenues for the other clusters. The lowest value is observed for cluster 1 (Japan and Korea). However, as far as total revenue on GPD is concerned the lowest share is observed for the cluster of Anglo-Saxon countries and the Asian countries, while all the European countries have larger levels of taxation, in particular cluster 3 and 4, which also have the highest values of average tax rate. Very different welfare systems characterized the clusters: especially low values of Gross Replacement Ratio (GRR) are observed for the cluster of Eastern European countries and the cluster 5 (Japan and Korea) while, as expected, the highest benefit for unemployment are in the Northern European countries but also in cluster 2 (composed by a variety of countries: Spain, France, Portugal, Ireland, and Netherlands). The same pattern is evidenced for Total Public Social Expenditures and Total Public Expenditures on passive labour market policies.

There are quite large differences in the level of Stock Market Capitalization to GDP, with the highest value in cluster 6 - the Anglo-Saxon countries - and the lowest value in cluster 4 and in cluster 1 (Eastern European countries). Finally, other influential indicators are the two indicators related to the technological level of the economic system: the Northern European countries (cluster 3 ) and Japan and Korea (cluster 5) exhibit the highest levels of investment in both R\&D and human capital, while the Eastern European countries have the lowest values for both these indicators.

From this descriptive analysis, one can draw some conclusions.

First of all, we find that the empirical support of the diversity of capitalism pointed out in Amable is largely confirmed. It is worth mentioning that it is not possible to identify a single European model of capitalism. The 19 European countries are split along five different clusters in both years. In addition to that, one can say that, with the exclusion of the United Kingdom, in 1995 the European countries were distributed among three different clusters, whereas fifteen years later the same countries were split into four different clusters. Apparently, this suggests that no process of convergence was at work in Europe in that period of time.

As far as Europe is concerned, the interpretation of cluster analysis with 2010 data suggests the existence of the following clusters: (i) a group of formerly centrally planned economies; (ii) a group of Scandinavian countries and Denmark; (iii) two clusters of continental countries which, in these fifteen years of interest, passed through a stage of institutional restructuring, which, however, did not imply any dynamics of convergence.

Second, an Anglo-Saxon model can be detected whose composition seems to be quite steady. Third, a stable cluster, which includes the two Asian countries, can be observed .

\subsubsection{Models of capitalism and inequality. Some preliminary empirical evidence}

In order to understand whether each cluster differs from the others as far as income distribution is concerned, one can estimate the following econometric model:

$$
\operatorname{gini}_{i, t}=\beta_{0}+\beta_{1} \text { cluster } 1+\beta_{2} \text { cluster } 2+\beta_{3} \text { cluster } 3+\beta_{4} \text { cluster } 4+\beta_{5} \text { cluster } 5+\epsilon_{i, t}
$$

The dependent variable ( gini $_{i, t}$ ) is a Gini index of income distribution for each one of the 24 countries. Cluster ${ }_{i}$ (where $i=1,2 \ldots 5$ ) is a dummy variable indicating the cluster of each country, based on cluster composition of 2010. Cluster 6 is the benchmark.

This preliminary econometric analysis shows some interesting results. First of all, considering that the cluster 6 is the benchmark of this straightforward model, one can observe that all the parameters are negative and highly significant; from a statistical point of view this means that the six clusters are statistically different as far as inequality in income distribution is concerned. The negativity of the signs for all the coefficients indicates that the cluster 6 (Australia, Canada, United Kingdom, 
United States and Switzerland) shows the highest degree of inequality in income distribution. It is important to remember that the higher is the absolute value of the coefficient related to the variable Cluster $_{i}$, the lower is the degree of inequality in income distribution. Therefore, one can state that the countries belonging to cluster 3 (Denmark, Finland, Norway, Sweden) evidence the lowest level of inequality in income distribution, whereas countries belonging to Cluster 2 (France, Ireland, Netherlands, Portugal and Spain) seem to be the closest, as far as income distribution is concerned, to the economies of cluster 6. Quite interestingly, the countries with formerly centrally planned economies (cluster 1, i.e.: Czech Republic, Poland, Slovak Republic and Hungary) show, at least in comparative terms, a low degree of income inequality.

Table 3 - Pooled OLS, using 384 observations - included 24 cross-sectional units - time-series length $=16$ Dependent variable: gini_net

\begin{tabular}{|c|c|c|c|c|}
\hline & coefficient & std. error & t-ratio & p-value \\
\hline Const & 32,4952 & 0,311187 & 104,4 & $7,30 \mathrm{e}-281 * * *$ \\
\hline Cluster 1 & $-5,15039$ & 0,466780 & $-11,03$ & $9,96 \mathrm{e}-025 * * *$ \\
\hline Cluster 2 & $-1,86836$ & 0,440085 & $-4,245$ & $2,75 \mathrm{e}-05 * * *$ \\
\hline Cluster 3 & $-8,61819$ & 0,466780 & $-18,46$ & $1,03 \mathrm{e}-054 * * *$ \\
\hline Cluster 4 & $-3,97942$ & 0,466780 & $-8,525$ & $3,70 \mathrm{e}-016 * * *$ \\
\hline Cluster 5 & $-2,30250$ & 0,582177 & $-3,955$ & $9,14 \mathrm{e}-05 * * *$ \\
\hline Mean dependent var & 28,95608 & S.D. dependent var & 3,968614 & \\
\hline Sum squared resid & 2928,361 & S.E. of regression & 2,783341 & \\
\hline R-squared & 0,514546 & Adjusted R-squared & 0,508125 & \\
\hline $\mathrm{F}(5,378)$ & 80,13052 & P-value $(F)$ & $3,53 \mathrm{e}-57$ & \\
\hline Log-likelihood & $-934,9310$ & Akaike criterion & 1881,862 & \\
\hline Schwarz criterion & 1905,566 & Hannan-Quinn & 1891,264 & \\
\hline Rho & 0,959376 & Durbin-Watson & 0,034028 & \\
\hline
\end{tabular}


Graph 1. The dynamics of income inequality1995-2010 (cluster 2010)。

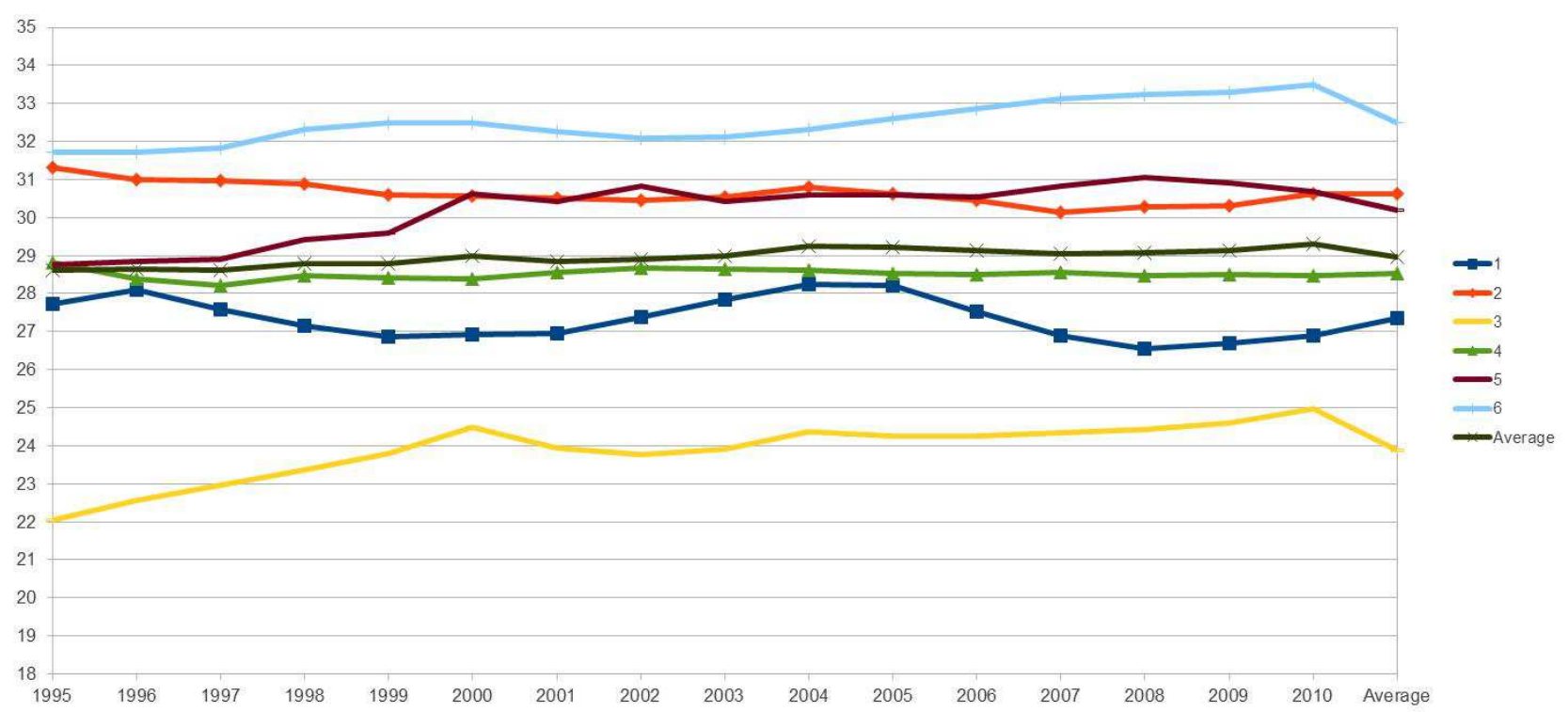

The straightforward econometric analysis can be watched through Graph 1. This graph shows the dynamics of inequality in the period 1995-2010, given the 2010 composition of clusters. Interestingly, we can observe a remarkable level of stability as far as the relative ranking of each cluster is concerned. Especially, as to European countries, the classification obtained through the cluster analysis seems to discriminate effectively the diverging performances of the countries in terms of income inequality.

\section{Issues in search for a new interpretation}

Three are the filters we have used for selecting the issues analysed in this paragraph. First, they must be related to the process of increasing inequality in some regions of the world. Second, MCT can be helpful in investigating it and therefore alternative solutions are available when choosing between different models of capitalism. Third, the notion of "symbolic violence" can contribute to improve the interpretation of their evolution in society.

In the case of the first two filters, we have already done some work which can be of some help for the present analysis. ${ }^{54}$ Even if we should stress the fact that the MCT has been worked out especially for comparing different models in a given point of time and investigating especially the distinctive characteristics of each model. While in our view a similar effort should be performed in studying also how specific models can evolve over time, and the impact of the evolution of each model on the sustainability of the others. A joint result of the latter effort could be relevant also in order to explore the attractiveness of established models on emerging powers and developing countries.

Moreover, for two of the issues considered in this paragraph we will make use of the metaphor of converging margins in the theory of plate tectonics. As suggested in (Antonelli, 2014), the theory of plate tectonics identifies three types of dynamics: (a) diverging margins, which separate the plates moving away one from another while shaping new earth crust in correspondence to oceanic ridges in this case the plate boundaries are defined ridges; (b) converging margins, along which two plates

\footnotetext{
${ }^{54}$ For instance, see Antonelli (2011, 2012, 2013, 2014).
} 
are moving toward each other and their match originates the immersion of a plate under the other or the collision between the two plates - in this case the plate boundaries are defined trenches; (c) transforms or conservative margins, along which the two plates slide horizontally one with respect to the other. Trenches are destructive plate margins, while ridges are constructive plate margins. ${ }^{55}$ Applying this metaphor to the evolution of economies, we can infer that without an early implementation of ambitious strategies of change in the economy and institutions, the economic structure can accumulate damaging effects on the sections less regulated or dealt with as residuals.

But the most complex task for economists and statisticians like us is to correctly deal with the very controversial notion of symbolic power or symbolic violence, which stem from philosophy and sociology and that, at least at first sight, could lead to an undue intrusion in different disciplines in which we do not have enough knowledge. ${ }^{56}$

A non arbitrary link between economic and sociological conceptions can perhaps be found through the notion of human capital. Following the suggestion of Portes (1998, p. 5): "The closest equivalent to human capital in Bourdieu's analysis is embodied cultural capital, which is defined as the habitus of cultural practices, knowledge, and demeanors learned through exposure to role models in the family and other environments" (Bourdieu, 1979). In this case Bourdieu seems to critically adjust a concept focused years in advance by the Chicago economists.

Another relevant thread is offered by one more comment of Portes (1998, p. 3), according to whom we owe the first systematic contemporary analysis of social capital to Bourdieu, who defined the concept as "... the aggregate of the actual or potential resources which are linked to possession of a durable network of more or less institutionalized relationships of mutual acquaintance or recognition. (Bourdieu 1985, p. 248; 1980)".

Since for Bourdieu inequality in modern society is due to unequal access to scarce resources, both in their material and immaterial meaning, all the three different types of capital ("economic", cultural and social) distinguished by him are relevant in interpreting inequality.

Social conflict rest very often on unequal access to resources and inequality. They can be engaged by a huge array of conflicting actors depending on the object of interest. Local and global social classes can be involved in them as well as different groups at variance with culture, gender, ethnicity, religion, race, age, sport and further characteristics.

Usually our interest is focused on dichotomic actors, like middle class and "underclass", incumbents and challengers or dissidents, immigrants and autochthons, heterodox and heretic. European economic literature has paid a lot of attention in the last decades to the insiders-outsiders dichotomy.

Put in this way, social conflicts are managed and solved not always by means of a rational, costbenefit, framework, but in an "opaque and subtle way" (Souza, 2011) which can be explained in terms of symbolic domination. As argued by Bourdieu (1979), symbolic domination or symbolic power is crucial in determining how hierarchies of power are structured and reproduced across societies. It is understood as the imposition of categories of thought and perception upon dominated social agents who, once they begin observing and evaluating the world in terms of those categories, perceive the existing social order as fair. This perpetuates the social structure which is favoured and serves the interests of the dominant agents. Therefore, symbolic power is much more powerful than physical violence in that it is embedded in the very modes of action and structures of cognition of individuals and legitimates the current social order.

\subsection{Labour markets in the EU and middle class decline}

The case of labour markets in EU can be relevant in explaining how different models of capitalism

\footnotetext{
${ }^{55}$ Further clarifications can be found in Condie (2003).

56 At the same time, we have to plainly recognize that the discussions within the GSP research team led us to acknowledge the relevance of this notion and of the background notions of capital in Bourdieu thought.
} 
interact and how inequality works through middle in Europe.

The economic systems in which labour markets operate in Europe are structurally diverse and this reflect the variety of regional economic systems and the persistence of different models of capitalism. $^{57}$

It is not possible and realistic to achieve, at least in a reasonable time interval, a unique labour market in Europe. Even in a more homogeneous institutional context different labour markets would continue to operate and this would generate several interactions among the diverse segments belonging to different countries. Moreover, the structural heterogeneity of European regions do not assist solutions devised mainly to take into account average behaviours of representative agents. In this respect, the adoption of a different approach, capable in allowing for the actual differences among diverse models of capitalism can help. This is true, also because in the European context it is long time that more models of capitalism are confronting themselves in a not much transparent way. This new approach allows for the recognition of the various relationships of action and reaction (feedback effects) which explain the linkages between labour markets, markets for goods and services and markets for production factors, innovation systems and institutions that discipline, both at the macro and micro-economic level, the different models. The diversity in the procedures which regulate these relationships bring about the variety among the economic systems which coexist within Eurozone and EU. Moreover, the way in which these subsystems are reciprocally related shape the different capability to react to the vicious dynamics of under-investment in human capital, stressed by Reich (1991).

On the other side, the inclusion of diverse labour markets in different models of capitalism helps in diminishing their residual character and strengthen their governance without ignoring their variety. In addition, it assists in exploring differentiated solutions, some of them transitory and other permanent, but all conceived in an evolutionary perspective. Furthermore, the possibility to compare different models of capitalism ${ }^{58}$ and let them compete with each other synchronically and evolve diachronically do not exclude further convergence processes and new solutions not yet predictable.

An important institutional feature distinguishing different models of capitalism can be found in the contractual condition and lay-off rules which are distinctive of the case law considered. When open-ended contracts prevail in labour markets these are related to totally different production organizations and financial institutions with respect to when fixed term contract prevail. Of course innovations bridging the gap between the two models can occur, but it is evident that the second setting requires perfect or quasi-perfect equilibria and passive flexibility in labour markets.

However, an overload of flexibility in labour markets, especially for the young persons, can discourage both the family, the worker and the firm to invest in general and specific education and training activities. This, in turn, may discourage innovation activities and investments. ${ }^{59}$ In very critical circumstances and in the long run passive flexibility and labour income uncertainty fostered by it can even determine human capital destruction, contradicting in this way the strategy of escaping the vicious dynamics of under-investment in human capital.

The capability to conceive the different subsystems as diverse models of capitalism may entail some advantages. The more so if the perspective of analysis includes both the synchronic and the diachronic dimensions. The diachronic dimension can be crucial both in finding new convergent paths and in assessing that old paths are not anymore sustainable for the future. For instance, on these grounds we could scrutinize if in our time the s.c. "Mediterranean model of capitalism" can be relevant in solving the integration issues while preserving the original characters of the Mediterranean regions or, rather, some of these characters could be better preserved through a transition to another model of capitalism which is more sustainable.

\footnotetext{
${ }^{57}$ For further clarifications, see Antonelli (2014).

${ }^{58}$ For example, through an formal exercise of open method of coordination (OMC).

${ }^{59}$ With reference to the Italian labour market see Bugamelli M., Cannari L., Lotti F. and Magri S. (2012).
} 
To give credit to the idea that the economic structure of the European regions is too diversified to be able to hold out at the same time the Euro system and a single and exclusive model of capitalism, and that, at least in certain cases, labour markets can fail in generating a stable equilibrium, means to live room to a diverse regulation of labour markets able to reduce the overall entropy and facilitate the identification of more sustainable intermediate trajectories.

This helps in clarifying, once for all, that the comparison among different regions, when implementing and evaluating EU policies, is to be made paying attention not mach to the average values but to the variances of the key variables. In this way, comparisons at a regional scale are privileged and functional aggregations in terms of "macro-areas" or "Euro-regions" are eligible. Moreover, since greater realism in the perception of economic policies at a supra-national level is allowed, the risk of systemic failure can be diminished and the wiggling competition among models carried out in the last two decades dismissed

Further advantages of the approach can be derived from its conceptual and analytical rigour. As a result, the definition of models of capitalism can help even in better categorizing and measuring labour markets. Moreover, it can help in screening the impact of different types of flexibility on development perspective of different sectors: for instance in the manufacturing industry recovery. It could also help in devising how to protect the choice of developing production activities from conflicting interests and appetites of the financial hubs that are taking off in EU countries, investing in different models of capitalism and exploiting at a full range the advantages of financialization of the global economy.

The phenomenon of converging margins in plate tectonics suggests that, when plates are converging, their contact can determine the immersion of one plate under another one or the collision between the two plates, that is an earthquake. ${ }^{60}$ When we use this analogy in the sphere of the European integration process these two consequences can be paralleled to two possible negative outcomes of this process. In the first case the process can lead to a demise of one of the converging parties, which is swallowed up by the other. In the second one it can lead to a breakdown of both parties and possibly to a systemic failure, and at least to a systemic risk. The third possible outcome, the only positive one, is not predicted in plate tectonics, but could be carried out in a political and institutional setting, being aware that the other two negative outcomes are not impossible and under some circumstances even more likely than the positive one.

In our view, the phenomenon of "employment polarization" and consequent middle class decline, which in Italy has taken the form of "detrimental convergence" 61 , can be better explained using this theoretical framework.

As already said, the ability of European regions and countries to face and solve in a cooperative way the problems deriving from their inner structural imbalances is crucial in motivating the interest of regions and countries of the global South for the European strategies of integration. Moreover, the changeover to an explicit comparison and competition among different models of capitalism does not exclude a potential long term convergence toward a unique model to the extent that the diachronic evolution may let emerge actual and prospective net benefits of each model both within the Eurozone and the EU.

\subsection{Flexicurity in European and Italian experience}

As we have seen in the introduction, the good side of inequality is strongly connected to the successes of competition and flexibility is one of its final outcomes.

\footnotetext{
${ }^{60}$ When the stress typology is considered, which is due to the different actions happening along the plates, three types of rupture mechanisms can be detected for earthquakes: direct or relaxed faults; reverse or compressive faults; translation faults. All possible combinations of these faults can occur.

${ }^{61}$ Observing the pattern of change in employment shares by wage terciles in the last fifteen years, the employment growth in Italy concentrates only on the job opportunities in high-wage and probably high-skill jobs. Job opportunities both in low-wage and probably low-skill jobs and in traditional middle-wage and probably middle-skill jobs have decreased (Autor and Katz, 2010).
} 
When we come to interpret the term competition, which is a kind of interaction between human beings crucial for economic growth and development as well as for economic success, again we can argue that its patterns and intensity are shaped by the institutional characteristics prevailing in the different models of capitalism in which they live.

John Kenneth Galbraith (1969, p. 96) maintained that in what he named the "conventional wisdom": "The desire for economic security was long considered the great enemy of increased product. This attitude was firmly grounded in the belief that the insecurity of the competitive model was essential for efficiency. ..... Plainly, however, the notion that economic insecurity is essential for efficiency and economic advance was a major miscalculation - perhaps the greatest in the history of economic ideas. ... In fact the years of increasing concern for economic security have been ones of unparalleled advance in productivity."

Galbraith, in criticizing the conventional wisdom, was taking advantage of the establishment of the high-volume manufacturing in the US and its capability to create "millions of jobs that swelled the ranks of American middle class" (Reich, 1991, p. 48). Nowadays the limited and polarized capability to increase the volume of jobs by the economies of developed countries drive us to consider an utopia the Galbraith's assessment: the match between insecurity and competition seems to have recovered a never-ending vigour.

However, insecurity fosters inequality and this trade-off seems to be evident in the historical experience of several developing countries (Adelman, 2000; Thirwall, 2012).

On the one side, we need competition in order to achieve a good economic performance but, on the other, we became aware that inequality, as a by-product of competition, can be unsustainable above certain thresholds and economic policies and appropriate institutions are essential in order to attain inclusive growth.

Since, however, social dumping and "competition from below" dominate the economic scene, we have to confront ourselves with the "dark side" of competition and not to appease ourselves with the fundamental theorems of welfare economics. And when we turn to the term social dumping, first we focus on a term "dumping" that has been carefully chosen to blame unfair practices of foreign traders. "It was said that foreigners were "dumping" their wares in the United States - a term conjuring up images of huge piles of substandard consumer durables and cheap novelty items littering American beaches." (Reich, 1991, p. 71)

Then, considering the attribute "social", we realize that it refers to many practices used by employers to hire cheaper labour, through both migrant workers and off-shoring, but, in absence of recognized "global legal standards" the precise nature of this unfairness is rarely stated with some specificity.

Consequently, governments have been tempted to enter a "social policy regime competition" through which they would lessen their labour and social standards in order to reduce labour costs on enterprises and to attract business activity within their jurisdiction. (Crouch, 2009) An unsaid threshold of the social dumping which is considered sustainable is implied in this approach. In this way "competition from below" is allowed by the "conventional wisdom".

Furthermore, what can be said about the raw production factor called "labour" applies also to the "broader production factor" that we could call "human resources" or "human capital". 62 At the same time, what is true for human resources is true also for the other "broad production factors": that is, environmental and natural resources, on the one side, innovation, technological change and physical capital, on the other. Social dumping occurs with reference to all broad production factors and often can take advantage from exploiting linkages and synergies between them.

If this reconstruction of the relationship between inequality, competition and social dumping is suitable, "legal global standards" should be defined at a world level in order to balance the mix between these components in a sustainable way for both developed and developing countries. In this way they would become a prerequisite of sustainable development. Under the aegis of the

\footnotetext{
${ }^{62}$ Including its education and qualification process through work based experience and learning.
} 
"decent work agenda" ILO has implemented several programmes at the global, regional and national levels. ${ }^{63}$ Particular attention has been paid to equal remuneration, the elimination of racial discrimination and better enforcement of legislation in general.

Since this is well known from many years, together with the severe risks faced by many countries in the case of an overload of flexibility in labour markets compromising human capital creation, we could wonder why the EU suggests as a best practice the "flexicurity model" which has been tested only in a small, wealthy, non Euro zone and, in this respect, unrepresentative country like Denmark? And why "outsiders", at least in countries like Italy, seem to accept a reform of the labour markets which tends to equalize their condition with that of "insiders" in a general frame of reduced job security and tenure cutback?

As far as the Italian situation is concerned, we can maintain with ISFOL (2013) that the deregulation of labour markets policies, implemented from the beginning of the '90s, did not led to improve neither productivity, nor job creation, or wages. Liberalization and disproportionate use of short term contracts and other forms of temporary works aimed at implementing more flexibility in labour markets initially rather rigid. But, while reducing the legal protection of some worker categories, they were not able to enhance, on the supply, side neither sales volumes of the firms nor job creation, on the contrary they even contributed to raise the cost of labour per product unit. At the same time, they have increased inequality, reduced the demand for consumption and worsened the crisis from the demand side.

A candidate explanation is that during the long phase of decline in economic conditions, preceding the global crisis, the misconduct of public and private sectors coupled with twisted mass communication, led many young outsiders to accept the view that they have been deprived by old insiders, understood as employees with tenure ${ }^{64}$, and impersonal mechanisms based on competition, meritocracy and flexibility are more fair.

\subsection{Migration between the two shores of the Mediterranean Sea}

The economic prospects of the Euro-Mediterranean Countries (EMCs) are uncertain, not only due to the long-lasting effects of the global crisis, social turbulence, political unrest and war, but also because of the impact of long term structural changes in the international division of labour and the shortage of political and institutional tools pre-arranged by EU and the international community at large.

The sequence of events taking place from 2011 in the Southern shore of the Mediterranean sea asks Europeans to reconsider the integration process, taking into account the new challenges and the deep interactions between the Northern and the Southern shores as well as to implement new priorities and regional economic unions.

We may even say that, after all, at least some of the many determinants of the "Arab spring" were not unpredictable. For sure, what has been called the "fever under the skin" of the Arab world heads to a brand new stage of development.

As it has been the case with the transformation of the Eastern-Central Europe Countries (ECECs) after the fall of the Berlin wall, the puzzle of the present crisis reflects many of the factors acting at a global scale: the impact of long term fragmentation in trade and production; the emergence of new economic powers; the changing composition of the population and of the working force.

In fact, if we take into account the proper time lag, we may note clear similarities between the ongoing transition of the ECEC and the potential transformation of the Arab League Countries (ALCs).

\footnotetext{
${ }^{63}$ Nondiscrimination has been included as a priority in the Decent Work Country Programmes of 36 countries. (ILO, 2011)

${ }^{64}$ Possibly organized in unions.
} 
For instance, the number of countries in each group is similar (27 countries and 22 respectively); the two groups of countries are similar in the size of projected population in 2030 (384.7 and 412.8 million), even if the latter exhibit a higher speed of growth and the median age is much lower.

Of course strong differences are also present: while the EU first comers countries are all included in the group with a very high HDI, the ECEC are concentrated in the group with high HDI and the ALC are mostly distributed between the high HDI group and the low HDI group. But this can be also consistent with the assimilation of the present events to a new transition process.

However, the key question is: how a new transition is likely to take place if EU, in competition/cooperation with the US, will not invest enough in it?

Structural and behavioural changes are now taking an accelerated speed, following a long run trend pre-existent to the global crisis: scale effects in many spheres of economic life (e.g., availability of broad production factors, production and trade); diversification in the models of capitalism; variety in economic leadership (e.g., China, with its 38,800 workers in Libya evacuated in quick time, but also Brazil as observer state in the Arab League, are very influent in the Mediterranean area); supply of new financial sources (e.g., sovereign funds from Saudi Arabia and Libya).

In labour markets deep changes are taking place on a multi layers basis: (i) in the composition of the labour force by age groups and generations; (ii) in the composition of the labour force by gender; (iii) in the composition of the labour force by educational qualifications; (iv) in the composition of the labour force by geographical origin; (v) the level of inequality is high and increasing.

Higher education graduates do not seem to represent anymore the main tool for shifting the production frontier. They are becoming, together with upper higher education diploma holders, the majority of the working force in the more advanced countries, and in the developing countries as well. The economic, but also the social and political role of education is changing over time.

This brings about several key research questions. Are labour market adjustments to be still conceived as the residual to the economic integration processes? Which role is played by mismatch, over-education, under-utilization of qualified manpower? Do we experience complementarities or substitution between the workforce of the two shores? To what extent labour markets governance can be one of the main determinants in regional integration processes?

The capability of European regions and countries to face and solve in a cooperative way the problems deriving from their inner structural imbalances should be coupled with the capacity to solve internal problems with an outward oriented approach.

With reference to labour markets and social convergence, three are the main implications. First, complementarities in demographic growth and labour force participation with the South Mediterranean regions and other regions of the global South should be explored, especially as far as future professional needs are concerned, in order to make the most of positive externalities. Second, educational and training initiatives at the various stages of the life cycle ${ }^{65}$ should be started on both sides of the Mediterranean shores in order to improve design and regulation of international flows of migration. The participation of business organizations would be a key component of these initiatives aiming at bridging the gap between the two shores. Third, regional cooperation plans concerned with the implementation of a new geography of jobs could be tested. Regional networks, involving not only neighbouring partners, could be engaged both in an offshore and inland creation of new job opportunities in the relevant sectors.

Of course many constraints limit the European capability to face this big issue. But why, instead of engaging thoroughly in it, the main matter of harsh political debate has become the Mare Nostrum operations in the Mediterranean sea? And why the local governors of the continental regions of Europe, while neglecting international rights and benefits incoming with the migrants human capital, argue about the suspension of the Schengen Treaty, aiming at excluding, rejecting and

\footnotetext{
${ }^{65}$ Higher education can play a crucial role in these strategies both in the education of the forthcoming local teachers and in the development of a qualified manpower.
} 
expelling migrant workers? Social tensions and hardening attitudes towards migrants lead to widespread discrimination and populist policies take advantage of this fostering greater xenophobia and discrimination directed towards migrants.

Also in this case a candidate explanation can be perhaps found in the day by day game of symbolic dominance played by immigrants and lower-middle class autochthones in which the former frequently interiorize the interests of the dominant agents. ${ }^{66}$

\subsection{Does it exists a leading model for Emerging Countries?}

Accepting variety in the way capitalism institutionally organize its functioning in different regions of the world does not amount to admit that no common structure lies beneath all capitalist societies. Financial capital and also cultural capital and social capital tend to preserve common fundamentals in each model.

Not even it can imply the acknowledgment that each model, once born, can be sustainable and able to persist for ever. We have seen that within each model an evolution can take place over time and this evolution can be influenced by the interactions between the different models of capitalism.

However, the joint action of the synchronic and diachronic dimensions makes the analysis very complex for reaching clear cut results at this stage. Intuition can be of some help, but is also subject to multiple mistakes. Therefore, for the time being no easy answer can be reached.

In any case, the competition between the different models can be expected quite strong due to the frictions caused by the combination of common fundamentals with diversity in interrelated subsystems. Moreover, the competition is fostered by the conviction that a zero sum game is being played.

If we apply to the interaction between developed countries and emerging powers the metaphor of converging margins in the theory of plate tectonics (Antonelli, 2014), we can reach, at least in principle, similar results compared to those we can reach when applying it to the EU scaffold.

Starting from highly differentiated economic conditions, the Emerging Powers are confronted with a triple corners' choice. On the first corner, each one of them could be driven to imitate the model of capitalism prevailing in the developed countries with which they are connected in terms of trade and economic interdependences. On the second one, each one of them could be pushed to adapt to the model of capitalism which is perceived as nearer to their starting conditions, in order to simplify the traverse path and maintain more autonomy. On the third corner, each one of them should take carefully in consideration the reciprocal interdependencies with the other Emerging Powers, and, more generally, with the global South.

Therefore, if, on the one hand, more degrees of freedom in adapting their economic policies to their strategies are available to Emerging Powers compared with EU, on the other, they can suffer more heavy constraints in terms of global interdependence feedbacks.

Apart the always possible occurrence of diverging or transforms/conservative margins, which sounds as rather optimistic in the midst of a global crisis, we can easily predict that the case of converging margins will prevail.

In this case, it is also easy to foresee that the most damaging effects will accrue, even for Emerging Powers, to the sections of their economic structure less regulated, or dealt with as residuals, in the adopted strategies. In particular no monetary zone can be designed without coherent strategies of convergence in labour markets.

Moreover, positive-sum game outcomes, which are not predicted in plate tectonics, could be carried

\footnotetext{
${ }^{66}$ In many countries migrant workers make up 8 to 20 per cent of the labour force, and in certain regions the figure is significantly higher. They face widespread pervasive discrimination in access to employment, and many encounter discrimination when employed. Migrant workers have been particularly affected by the economic crisis, with reduced employment or migration opportunities and increased xenophobia, a deterioration in working conditions and even violence. Unfair working conditions are faced by migrants in both developed and developing countries. (ILO, 2011, p. xii)
} 
out in the political and institutional setting, but they require prudent and proactive foresight, long term planning and competent governance.

\section{Conclusion}

From this articulated paper it is quite complicated to draw some synthetic conclusions, as it is full of possible paths of development for future research both from a theoretical and an empirical perspective. Therefore, one has to limit to draw only few conclusions in order to focus the attention on some highly relevant and selected problems, considering that this does not exhaust the possible issues which can be taken into account. In our opinion one can work out two distinct levels of discussion as a conclusive stage of this paper; a methodological level, based on the methodologies adopted and the theories introduced and furthered and an empirical level, based on the non-trivial results obtained in the quantitative analysis.

From a methodological point of view this paper has emphasized how institutions affect the definition of the notion of model of capitalism. Of course, the analysis of the role of institutions on the functioning of markets for goods, capital and services and on the economic system as a whole is not new at all. Nowadays, whatever approach she/he decides to adopt, no economist would dream of denying the pivotal role played by institutions for the determination of the performances of markets. But in the analysis developed in this contribution institutions play a role which is quite at odds with other approaches for which institutions are a cornerstone. First of all, in our approach, institutions define the model of capitalism itself regardless of any interpretative economic model. This, of course, does not mean that micro and macro-economic models are irrelevant if one wants to understand and analyze the dynamics and the interactions of economic variables. But the complex and interrelated fabric of institutions which establish among themselves a complex cobweb of complementary relationships (positive or negative) provide the background on which the economic variables interact and affect each other. In this approach institutions are not only a constraint on the dynamics of economic variables or on their paths of quantitative adjustments. Institutions contribute to define the economic variables themselves in the sense that without institutions we would not be able to observe, for example, the interactions between demand and supply on a market for goods and services. Hence, in this sense, institutions can be considered as resources at disposal of economic actors and not simply as constraints to the behaviour of maximising individuals. In addition to that, institutions and the way these evolve explain the role of time and path dependence in the determination of economic variables; the level of a variable $X$ at time $t$ depends also on the level of a variable at time $t-1$ and affects what will occur to the variable at time $t+1$. History matters. This way to conceive institutions is consistent with Rehbein and Souza's (2014, p. 20) approach, when, in their paper affirm: "Social structures, cultures and practices are subject to constant transformations and sometimes even revolutions. New institutions appear, old ones are done away with, new discourses emerge, economic crises erupt or oil is discovered. These transformations have an impact on the configurations of inequality. However, these do not appear out of the blue but literally are transformations of earlier configurations. Structures of inequality are relatively persistent. Aristocracy or working class, the value of a $\mathrm{PhD}$ or the reputation of doctors do not disappear overnight. The structures, on which they are based, change even slowlier, but they do change. Through social revolutions new cultural frameworks for inequality emerge. We refer to these frameworks as sociocultures. As sociocultures persist, so do forms of action or institutions that appear outdated. Monarchic rituals, bar associations, village structures or sociolects would be examples for this". This approach is very close to our approach where the institutions and their relationships define the model of capitalism which, in turn, affect the level and the dynamics of income inequality.

In this paper there is second methodological point which is worth mentioning and can be considered as another point of contact with Rehbein and Souza's approach. As a matter of fact, despite we focus our attention on inequality in income distribution, we have claimed the relevance of 
inequality as a multi-dimensional phenomenon. Summarizing briefly what we said in the initial part of this contribution, we can say that we do not conceive inequality as unequal distribution of material resources, but also, at least, as unequal access to educational opportunities and/or to health services. This is very strictly related to the idea of social "milieux" developed by Vester and, later, adopted by Rehbein and Souza as the educational opportunities and the access to health services can be considered as a constituent element of the social milieux.

Turning to the results obtained in the empirical analysis of inequality, the analysis allows to draw some preliminary conclusions about the alleged process of convergence in progress in both the EU and at a world level, as a consequence of the process of globalisation. As to the first point the empirical evidence outlined in this work shows that there is not a European model of capitalism and apparently European countries are not converging. This is quite surprising because in the interval between 1995-2010 the introduction of Euro pushed towards the convergence of fiscal policies. Apparently, this did not promote a process of convergence, as the discussion about labour markets in the EU and middle class decline has demonstrated. The EU policies did not manage to merge the different economies into a single model of capitalism. As to the effects of the process of globalisation, the empirical analysis developed in this paper has said nothing. Therefore, it seems to be extremely important to extend the analysis by focusing on emerging countries. One of the big questions is to understand if these countries are converging towards an existing model or if they are creating a new one. Does globalisation foster the convergence towards a single model, or does the path-dependency effect prevail with the creation of new and, at the moment, unpredictable models? An answer could be experimented only when we will be able to other explore other dimensions of inequality in terms of effects, while we already have been able to take into account of different dimensions in terms of determinants and basic characteristics, finding proper statistical indicators and proper data-bases. 


\section{References}

Adelman (2000), Fifty years of economic development: What have we learned?, Paper prepared for the World Bank European Annual Bank Conference on Development Economics, World Bank, Washington, D.C.

Albert M. (1991), Capitalisme contre capitalisme, Paris, Editions du Seuil.

Amable B. (2000), Institutional complementarity and diversity of social systems of innovation and production, Review of International Political Economy, Vol. 7, N 4, pp. 645-687.

Amable B. (2003), The diversity of modern capitalism, Oxford, Oxford University Press

Antonelli (1997), Broad production factors and technological systems", in G. Antonelli and N. De Liso (eds.), Economic analysis of structural change and technical progress, London, Routledge, pp. 86-106.

Antonelli (2011), Emerging powers development, global economic crisis and value chains restructuring, in B. Rehbein (ed.) (2011), pp.175-193.

Antonelli (2012), Investigating the impact of different conceptions and measurement of inequality on economic trends: A causal reversal in the relationship between inequality and economic development?, Joint Conference between Humboldt University and University of Bologna on "Social and economic inequality", November.

Antonelli (2013), Structural economic dynamics and multi-dimensional inequality, Focus Asia Workshop on "Entrenched Inequalities: East and West", Centre for East and South-East Asian Studies, Lund University, March.

Antonelli (2014), Knowledge based competition, convergence in labour markets and models of capitalism in Europe, Transcience. A Journal of Global Studies, Vol. V, N. 1, pp. 79-90.

Aoki, M. (2001), Toward a comparative institutional analysis, Cambridge, Mass, MIT Press.

Arthur, W.B. (1994), Increasing returns and path dependency in the economy, Ann Arbor, University of Michigan Press.

Autor D.H. and Katz L.F. (2010), Grand challenges in the study of employment and technological change: A white paper prepared for the National Science Foundation, Harvard University and NBER, September.

Becker G. (1957), The economics of discrimination, Chicago, University of Chicago Press, 2d ed. 1971.

Becker G. (1993), Nobel lecture. The economic way of looking at behaviour, Journal of Political Economy, Vol. 101, N. 3, pp. 385-409.

Berloffa G. and Segnana M.L. (2006), Trade, poverty and growth: two perspectives, one message?, in Salvadori N. (ed.), Economic growth and distribution. On the nature and causes of the wealth of nations, Cheltenham, Edward Elgar, pp. 374-412.

Bourdieu P. (1979), Les trois états du capital culturel, Actes de la Recherche en Sciences Sociales, Vol. 30, N. 30, p. 3-6.

Bourdieu P. (1985), The forms of capital, in J. Richardson (ed.), Handbook of theory and research for the sociology of education, New York, Greenwood, pp. 241-258.

Bugamelli M., Cannari L., Lotti F. and Magri S. (2012), Il gap innovativo del sistema produttivo italiano: radici e possibili rimedi, Questioni di Economia e Finanza (Occasional papers), N. 121, April.

Condie K.C. (2003), Plate tectonics and crustal evolution, Oxford, Butterworth-Heinemann, Fourth edition.

Crouch C. (2009), Privatised keynesianism: An unacknowledged policy regime, The British Journal of Politics and International Relations, Vol. 11, 382-399.

Crouch C. (2010), Complementarity, in G. Morgan, J. Campbell, C. Crouch, O.K. Pedersen and R. Whitley (eds.), (2010), The Oxford handbook of comparative institutional analysis, Oxford, Oxford University Press.

Crouch C., Streeck W., Boyer R., Amable B., Hall P.A. and Jackson G. (2005), Dialogue on Institutional complementarity and political economy, Socio-Economic Review, N. 3, pp. 359- 
Cunha F., Heckman J. and Schennach S. (2010), Estimating the technology of cognitive and noncognitive skill, NBER Working Paper Series, N. 15664, February.

David, P.A. (1994), Why are institutions the "carriers of history"? Path dependence and the evolution of conventions, organizations and institutions, Structural Change and Economic Dynamics, vol. 5, pp. 205-20.

Everitt B. (1979), Unresolved problems in cluster analysis, Biometrics, Vol. 35, N. 1, pp. 169-181.

Everitt B., Dunn G. (2001), Applied multivariate data analysis, London, Arnold Publishing.

Hall, P. A., Soskice, D. (eds.) (2001) Varieties of capitalism: The institutional foundations of comparative advantage, Oxford, Oxford University Press.

EU (2010), Charter of fundamental rights of the European Union, Official Journal of the European Union (2010/C 83/02).

Freeman R.B. (2000), Single peaked vs. diversified capitalism: The relation between economic institutions and outcomes, NBER Working Paper 7556, National Bureau of Economic Research, February.

Galbraith J.K. (1969), The affluent society, New York, Houghton Mifflin Company, II ed.

Howell D.R. and Huebler F. (2001), Trends in earnings inequality and unemployment across the OECD: Labor market institutions and simple supply and demand stories, CEPA Working Paper, Center for Economic Policy Analysis, New School University, New York, May.

Kanbur R. and Lustig N. (1999), Why is inequality back on the agenda? Paper prepared for the Annual Bank Conference on Development Economics, World Bank, April.

Kang N. (2006), Analysing 'system change': The role of institutional complementarity in corporate governance, International Centre for Corporate Social Responsibility, Nottingham University Business School, Research Paper Series N. 43.

Kuznets S. (1955), Economic growth and income inequality, The American Economic Review, Vol. 45, N. 1., March, pp. 1-28.

ILO (2011), Equality at work: The continuing challenge, Geneva, International Labour Office.

IMF (2003), Unemployment and labor market institutions: Why reforms pay off, in IMF (2003), Economic outlook, April, Washington, Cap. IV, pp. 129-150.

Institute for Development Studies (IDS) (2009), After 2015: Rethinking Pro-Poor Policy, IDS in Focus Policy Briefing, Issue 09.

ISFOL (2013), Mercato del Lavoro, capitale umano ed imprese: una prospettiva di politica del lavoro, Roma, ISFOL, 2013.

Marmot M. (2013), Fair society, healthy lives, Florence, Casa Editrice Leo S. Olschki.

Mazzocchi M., Statistics for marketing and consumer research, London, Sage Publications.

McGregor J.A. (2007), Researching well-being: From concepts to methodology" in I. Gough and J. A. McGregor (eds.), Wellbeing in developing countries, Cambridge: Cambridge University Press.

Niskanen E. (2007), The Luxembourg wealth study: Technical report on LWS income variables, Luxembourg Income Study Technical Paper Series, N. 2.

North D.C. (1990), Institutions, institutional change and economic performance, Cambridge, Cambridge University Press.

Piketty T. (2014), Capital in the twenty-first century, Cambridge Mass., The Belknap Press of Harvard University Press.

Portes A. (1998), Social capital: Its origins and applications in modern sociology, Annual Review of Sociology, Vol. 24, pp.1- 24.

Prodi (1991), C'è un posto per l'Italia tra i due capitalismi?, Il Mulino, N. 1, gennaio-febbraio, pp. pp. 21-33.

Rehbein B. (ed.) (2011), Globalization and inequality in emerging societies, Houndmills, Palgrave 
Macmillan.

Rehbein B.and Souza J. (2014), Inequality in Capitalist Societies, Transcience. A Journal of Global Studies, Vol. 5, N. 1, pp. 16-27.

Reich R. (1991), The work of nations, Vintage Books, New York.

Sala-i-Martin X. (2002), The disturbing "rise" of global income inequality, National Bureau of Economic Research, WP 8904, April.

Schettkat R. (2003), Institutions in the economic fitness landscape: What impact do welfare state institutions have on economic performance?, Institute for the Study of Labor, IZA, Bonn, January, mimeo.

Shy O. (2001), The economics of network industries, Cambridge, Cambridge University Press.

Souza J. (2011), Are the Brasilian lower classes universal? Towards a critical theory of modernization, in B. Rehbein ced.) (2011), pp. 71-91.

Sumner A. and Mallett R. (2013), Capturing multidimensionality: What does a human wellbeing conceptual framework add to the analysis of vulnerability?, Social Indicators Research, Vol. 113 , N. 2, p. 671-690.

Teixeira P.N. (2003), Forging modern labour economics, Paper presented at the annual meeting of the European Association for Evolutionary Political Economy, Maastricht, November.

Thirlwall A.P. (2013), The rhetoric and reality of trade liberalization in developing countries, Rivista Italiana degli Economisti, Vol. 18, N. 1, pp. 3-24.

UNDP (2013), Humanity divided: Confronting inequality in developing countries, New York, United Nations Development Programme.

UNDP (2014), Human Development Report 2014. Sustaining human progress: Reducing vulnerabilities and building resilience, New York, United Nations Development Programme.

Zenezini M. (2006), Sono davvero importanti le istituzioni del mercato del lavoro per capire la disoccupazione?, Dipartimento di Scienze Economiche e Statistiche, Università di Trieste, Working Paper N. 103. 


\section{APPENDIX}

\section{Cluster Analysis}

The Cluster Analysis (CA) is an exploratory data analysis tool for organizing observed data (e.g. people, things, events, brands, companies) into meaningful taxonomies, groups, or clusters, based on combinations of certain variables that describe units' characteristics, which maximizes the similarity of cases within each cluster while maximizing the dissimilarity between groups that are initially unknown. In this sense, CA creates new groupings without any notion of what clusters may arise. CA provides no explanation as to why the clusters exist nor is any interpretation made. Each cluster thus describes, in terms of the data collected, the class to which its members belong. Items in each cluster are similar in some ways to each other and dissimilar to those in other clusters.

There are two basic approaches for generating a hierarchical clustering: i) agglomerative (are by far the most common techniques): start with two points as individual clusters and, at each step, merge the closest pair of clusters. This require defining a notion of cluster similarity or distance; ii) divisive: start with one all-inclusive cluster and, at each step, split a cluster until only a singleton clusters of individual points remain; in this case we need to decide which cluster to split at each step and how to do the splitting.

Many agglomerative hierarchical clustering techniques are variation on a single approach: starting with individual point as clusters, successively merge the two closest clusters until one cluster remains. The merge of two clusters at each step is based on a measure of similarity or distance between the two cluster to be merged. The definition of cluster similarity differentiates the various agglomerative hierarchical techniques (for more detail see, for example, Everitt et al. 2001).

In this application we use the WARD's Minimum Variance Method, that assumes that a cluster is represented by its centroid and measures the distance between two cluster in terms of the increase in the within-clusters Sum of Squares (SSE) that result merging the two clusters. This methods attempts to minimize the sum of the squared distances of points from their cluster centroids.

If we indicate as $\boldsymbol{x}$ the vector of the observed variables, in the Ward's minimum-variance method the distance between two clusters $\mathrm{K}$ and $\mathrm{L}$ is defined by:

$$
D_{K L}=\frac{\left\|\overline{\boldsymbol{x}}_{K}-\overline{\boldsymbol{x}}_{L}\right\|^{2}}{\frac{1}{N_{K}}+\frac{1}{N_{L}}}
$$

where $\left\|\overline{\boldsymbol{x}}_{K}-\overline{\boldsymbol{x}}_{L}\right\|^{2}$ is the square of the Euclidian distance between the centroids of the clusters $\mathrm{K}$ and $\mathrm{L}$ (the centroid is the mean vector in the group for all the variables), and $N_{K}$ and $N_{L}$ are the the number of observations in the clusters $\mathrm{K}$ and $\mathrm{L}$.

The distance between the two clusters is the ANOVA sum of squares (between-cluster sum of squares) between the two clusters added up over all the variables. At each generation, the withincluster sum of squares is minimized over all partitions obtainable by merging two clusters from the previous generation. The total sum of squares are easier to interpret when they are divided by the total sum of squares to give proportions of variance. At each step of the procedure, the square multiple correlation ( $\mathrm{R}$-square) is the proportion of total variance accounted for by the clusters. The semi-partial R-square represents the decrease in the proportion of variance accounted for by joining two clusters.

When carrying out a hierarchical cluster analysis, the process can be represented on a diagram known as a dendrogram. This diagram illustrates which clusters have been joined at each stage of the analysis and the distance between clusters at the time of joining (this is usually the semi-partial $\mathrm{R}$-square). If there is a large jump in the distance between clusters from one stage to another then this suggests that at one stage clusters that are relatively close together were joined whereas, at the 
following stage, the clusters that were joined were relatively far apart. This implies that the optimum number of clusters may be the number present just before that large jump in distance. This is easier to understand by actually looking at the dendrogram, like the one reported in Figure 1 and 2. The choice of the number of cluster to consider can be done visually looking at the dendrogram. A more formal rule for the choice of the number of clusters is those based on the pseudo F statistic calculated at each step of the procedure. The pseudo F statistic is the ratio of between-cluster to within-cluster sum of squares, divided respectively by the numbers $\mathrm{g}-1$ and $\mathrm{N}-\mathrm{g}$, where $\mathrm{g}$ is the number of clusters. A relatively large value (compared to the preceding and the following values in the series) indicates a stopping point.

\section{TABLES}

\section{Table A.1: Definition of institutional indicators}

\begin{tabular}{|c|c|}
\hline Indicator & Description and source \\
\hline $\begin{array}{l}\text { Public expenditures on Active } \\
\text { measures on Labour Market }\end{array}$ & $\begin{array}{l}\text { Public expenditures as a percentage of GDP on Active Labour market } \\
\text { policies (Active measures (20-70): Training - Employment incentives - } \\
\text { Sheltered and supported employment and rehabilitation - Direct job } \\
\text { creation- Start-up incentives): OECD Dataset: Public expenditure and } \\
\text { participant stocks on LMP; 1985-2011 }\end{array}$ \\
\hline $\begin{array}{l}\text { Public expenditure on Passive } \\
\text { Labour Market Policies } \\
\text { ( \% GDP) }\end{array}$ & $\begin{array}{l}\text { Public expenditures as a percentage of GDP on Passive Labour market } \\
\text { policies (Out-of-work income maintenance and support - Early } \\
\text { retirement): OECD Dataset: Public expenditure and participant stocks } \\
\text { on LMP; 1985-2011 }\end{array}$ \\
\hline $\begin{array}{l}\text { Public unemployment } \\
\text { expenditure (\% GDP) }\end{array}$ & $\begin{array}{l}\text { Public unemployment expenditure \% GDP: OECD Dataset: Social } \\
\text { Expenditure - Aggregated data; } 1995-2013\end{array}$ \\
\hline $\begin{array}{l}\text { Total public social expenditure } \\
(\% \text { GDP) }\end{array}$ & $\begin{array}{l}\text { Total public social expenditure \% GDP: OECD Dataset: Social } \\
\text { Expenditure - Aggregated data; 1995-2013 }\end{array}$ \\
\hline $\begin{array}{l}\text { Public expenditure on education } \\
\text { (\% on government expenditure) }\end{array}$ & $\begin{array}{l}\text { Public expenditure on education \% on government expenditures: UN; } \\
\text { 1970-2012 (selected years and countries) }\end{array}$ \\
\hline Wage coordination & $\begin{array}{l}\text { Wage setting coordination indicator: WCoord of Visser (2009 ICTWSS } \\
\text { data base). It is a five-point classification of wage-setting coordination } \\
\text { scores, ranging from one (no coordination or fragmented bargaining) to } \\
\text { five (economy-wide bargaining); 1985-2012. }\end{array}$ \\
\hline Trade union density & $\begin{array}{l}\text { Union density rate defined as the percentage of employees who are } \\
\text { members of a trade union (OECD Employment Database); 1985-?? }\end{array}$ \\
\hline Minimum wage/Median earning & $\begin{array}{l}\text { The ratio of minimum-to-median earnings. Minimum wages are } \\
\text { measured relative to the median value of basic earnings (excluding } \\
\text { overtime and bonus payments) of full-time employees: OECD } \\
\text { Employment Database, 2000-2011. }\end{array}$ \\
\hline Average Tax wadge (\%) & $\begin{array}{l}\text { Average Tax wadge (\%) for a single person at } 100 \% \text { of average } \\
\text { earnings, no child; OECD: Taxing wages (comparative tables); 2000- } \\
2012\end{array}$ \\
\hline
\end{tabular}


Continue Table A.1

Indicator

Gross replacement ratio

Share of temporary employment

Employment protection

Temporary employment protection

Product market Protection - State Control

Product market Protection -

Barrier to entrepreneurship

Product market Protection -

Barrier to trade and investments

Domestic credit provided by banking sector (\% of GDP)

Domestic credit to private sector (\% of GDP)

Bank concentration (\%)

Percentage of foreign banks among total banks (\%)

Stock market capitalization to GDP $(\%)$

Stock market total value traded to GDP $(\%)$

\section{Description and source}

Gross replacement ratio - Gross replacement rates are calculated as gross unemployment benefit levels divided by previous gross earnings (average worker as reference); source OECD: Benefits and Wages database, 1995-2000 (yearly); 2001-2011 (every two years)

Share of temporary employment; OECD LFS dataset: "Employment by Permanency"; 1995-2012

Employment protection indicator (regular contracts): OECD

Employment Database; 1985-2013

Employment protection indicator (temporary contracts): OECD

Employment Database; 1985-2013

Product Market Regulation index: State control; OECD PMR indicators database, 1998-2003-2008

Product Market Regulation index: Barrier to entrepreneurship; OECD PMR indicators database, 1998-2003-2008

Product Market Regulation index: Barriers to trade and investments; OECD PMR indicators database, 1998-2003-2008

Domestic credit provided by banking sector (\% of GDP): includes all credit to various sectors on a gross basis, with the exception of credit to the central government. The banking sector includes monetary authorities and deposit money banks, as well as other banking institutions. World Bank, JOBS database; 1995-2011

Domestic credit to private sector (\% of GDP): financial resources provided to the private sector, such as through loans, purchases of nonequity securities, and trade credits and other accounts receivable, that establish a claim for repayment: World Bank, JOBS database; 19952011

Bank concentration (\%):World Bank, Global financial indicators database; 1995-2011

Percentage of foreign banks among total banks (\%):World Bank, Global financial indicators database; 1995-2011

Stock market capitalization to GDP (\%):Total value of all listed shares in a stock market as a percentage of GDP; World Bank, Global financial indicators database; $1995-2011$

Stock market total value traded to GDP (\%): Stocks traded refers to the total value of shares traded during the period. This indicator complements the market capitalization ratio by showing whether market size is matched by trading. World Bank, Global financial indicators database; 1995-2011 
Indicator

Stock market turnover ratio (value traded/capitalization) (\%)

Average income tax rate $(\%)$

Net personal marginal tax rate: Principal earner (\%)

Marginal tax wedge: Principal earner $(\%)$

Total tax revenue on GDP

Taxes on income, profits and capital gains (\% total tax)

Social security contributions (\% total tax)

Taxes on goods and services (\% total tax)

Gross domestic expenditure on R\&D (\% of GDP)

Total researchers per thousand total employment

Percentage of GERD financed by government

Percentage of GERD financed by private sector

\section{Description and source}

Stock market turnover ratio (value traded/capitalization) (\%): total value of shares traded during the period divided by the average market capitalization for the period. Average market capitalization is calculated as the average of the end-of-period values for the current period and the previous period: World Bank, Global financial indicators database; 1995-2011

Average income tax rate (\%); income taxes paid by workers divided the earning of the Average Worker for a single person at $100 \%$ of average earnings, no child; OECD Taxing wages dataset; 2000-2012.

Net personal marginal tax rate: Principal earner (\%); OECD Taxing wages dataset; 2000-2012

Marginal tax wedge: Principal earner (\%); OECD Taxing wages dataset; 2000-2012

Total tax revenue on GDP; OECD Revenue statistics - Comparatives Series dataset; 1995-2012

Taxes on income, profits and capital gains (\% total tax); OECD

Revenue statistics - Comparatives Series dataset; 1995-2012

Social security contributions (\% total tax); OECD Revenue statistics Comparatives Series dataset; 1995-2012

Taxes on goods and services (\% total tax); OECD Revenue statistics Comparatives Series dataset; 1995-2012

GERD (Gross Domestic Expenditure on R\&D) as a percentage of GDP: OECD Main Science and technology indicators Dataset; 1995-2011

Total researchers per thousand total employment : OECD Main Science and technology indicators Dataset; 1995-2011

Percentage of GERD financed by government: OECD Main Science and technology indicators Dataset; 1995-2011

Percentage of GERD financed by private sector: OECD Main Science and technology indicators Dataset; 1995-2011 
Table A.2. Cluster history, 1995

\begin{tabular}{|c|c|c|c|c|c|c|c|}
\hline $\begin{array}{l}\begin{array}{l}\text { Number } \\
\text { of } \\
\text { clusters }\end{array} \\
\end{array}$ & Clus & joined & Freq & $\begin{array}{r}\text { Semipartial } \\
\text { R-square }\end{array}$ & R-square & $\begin{array}{r}\text { Pseudo F } \\
\text { statistic }\end{array}$ & $\begin{array}{r}\text { Pseudo } \\
\text { t-square }\end{array}$ \\
\hline 23 & Australia & Canada & 2 & 0.0073 & 0.993 & 6.2 & \\
\hline 22 & Finland & Sweden & 2 & 0.01 & 0.983 & 5.4 & \\
\hline 21 & Austria & Germany & 2 & 0.0106 & 0.972 & 5.2 & \\
\hline 20 & Czech Republic & Slovakia & 2 & 0.0107 & 0.961 & 5.2 & \\
\hline 19 & CL23 & United Kingdom & 3 & 0.0164 & 0.945 & 4.8 & 2.2 \\
\hline 18 & CL21 & Italy & 3 & 0.0166 & 0.928 & 4.6 & 1.6 \\
\hline 17 & CL18 & France & 4 & 0.0189 & 0.91 & 4.4 & 1.4 \\
\hline 16 & CL22 & Norway & 3 & 0.0217 & 0.888 & 4.2 & 2.2 \\
\hline 15 & CL19 & United States & 4 & 0.024 & 0.864 & 4.1 & 2 \\
\hline 14 & Denmark & CL16 & 4 & 0.026 & 0.838 & 4 & 1.6 \\
\hline 13 & Portugal & Spain & 2 & 0.0269 & 0.811 & 3.9 & \\
\hline 12 & Belgium & Netherlands & 2 & 0.0271 & 0.784 & 4 & \\
\hline 11 & CL20 & Poland & 3 & 0.0301 & 0.754 & 4 & 2.8 \\
\hline 10 & Japan & Switzerland & 2 & 0.0307 & 0.723 & 4.1 & \\
\hline 9 & CL17 & CL12 & 6 & 0.033 & 0.69 & 4.2 & 1.8 \\
\hline 8 & Hungary & Ireland & 2 & 0.037 & 0.653 & 4.3 & \\
\hline 7 & CL11 & CL13 & 5 & 0.0454 & 0.608 & 4.4 & 2 \\
\hline 6 & CL7 & CL8 & 7 & 0.0512 & 0.556 & 4.5 & 1.7 \\
\hline 5 & CL10 & Korea & 3 & 0.0519 & 0.504 & 4.8 & 1.7 \\
\hline 4 & CL9 & CL14 & 10 & 0.079 & 0.425 & 4.9 & 3.9 \\
\hline 3 & CL15 & CL5 & 7 & 0.079 & 0.346 & 5.6 & 3 \\
\hline 2 & CL4 & CL6 & 17 & 0.1229 & 0.224 & 6.3 & 4.1 \\
\hline 1 & CL3 & CL2 & 24 & 0.2235 & 0 & . & 6.3 \\
\hline
\end{tabular}


Table A.3. Cluster history, 2010

\begin{tabular}{|c|c|c|c|c|c|c|c|}
\hline $\begin{array}{l}\text { Number } \\
\text { of cluster }\end{array}$ & Clus & Joined & Freq & $\begin{array}{r}\text { Semipartial } \\
\text { R-square }\end{array}$ & R-square & $\begin{array}{r}\text { Pseudo F } \\
\text { Statistic }\end{array}$ & $\begin{array}{r}\text { Pseudo } \\
\text { t-squared }\end{array}$ \\
\hline 23 & Austria & Germany & 2 & 0.0072 & 0.993 & 6.2 & \\
\hline 22 & Canada & United Kingdom & 2 & 0.0078 & 0.985 & 6.2 & \\
\hline 21 & Czech Republic & Slovakia & 2 & 0.0089 & 0.976 & 6.1 & \\
\hline 20 & Netherlands & Portugal & 2 & 0.0122 & 0.964 & 5.6 & \\
\hline 19 & Australia & CL22 & 3 & 0.0127 & 0.951 & 5.4 & 1.6 \\
\hline 18 & Finland & Sweden & 2 & 0.0134 & 0.938 & 5.3 & \\
\hline 17 & CL23 & Italy & 3 & 0.0163 & 0.921 & 5.1 & 2.3 \\
\hline 16 & CL20 & Spain & 3 & 0.019 & 0.902 & 4.9 & 1.6 \\
\hline 15 & CL21 & Hungary & 3 & 0.0228 & 0.879 & 4.7 & 2.6 \\
\hline 14 & France & CL16 & 4 & 0.0238 & 0.856 & 4.6 & 1.5 \\
\hline 13 & CL18 & Norway & 3 & 0.0239 & 0.832 & 4.5 & 1.8 \\
\hline 12 & Denmark & CL13 & 4 & 0.027 & 0.805 & 4.5 & 1.4 \\
\hline 11 & CL19 & United States & 4 & 0.0278 & 0.777 & 4.5 & 2.7 \\
\hline 10 & CL11 & Switzerland & 5 & 0.0316 & 0.745 & 4.6 & 2 \\
\hline 9 & Japan & Korea & 2 & 0.0357 & 0.71 & 4.6 & \\
\hline 8 & CL15 & Poland & 4 & 0.0365 & 0.673 & 4.7 & 2.3 \\
\hline 7 & CL14 & Ireland & 5 & 0.0375 & 0.636 & 4.9 & 2.1 \\
\hline 6 & CL17 & Belgium & 4 & 0.0423 & 0.593 & 5.3 & 3.6 \\
\hline 5 & CL10 & CL9 & 7 & 0.0533 & 0.54 & 5.6 & 2.3 \\
\hline 4 & CL6 & CL12 & 8 & 0.0591 & 0.481 & 6.2 & 2.7 \\
\hline 3 & CL4 & CL7 & 13 & 0.0902 & 0.391 & 6.7 & 3.5 \\
\hline 2 & CL3 & CL8 & 17 & 0.1755 & 0.215 & 6 & 6 \\
\hline 1 & CL5 & CL2 & 24 & 0.2153 & 0 & & 6 \\
\hline
\end{tabular}


Table A.4 Cluster Averages for each indicator, 1995

\begin{tabular}{|c|c|c|c|c|c|}
\hline & \multicolumn{5}{|c|}{ CLUSTER } \\
\hline & 1 & 2 & 3 & 4 & 5 \\
\hline Public expenditure on Active Labour Market Policies ( $\%$ on GDP) & 0.44 & 1.49 & 0.72 & 0.26 & 0.27 \\
\hline Average income tax rate $(\%)$ & 12.54 & 27.29 & 18.31 & 6.66 & 20.18 \\
\hline Bank concentration $(\%)$ & 64.38 & 87.68 & 61.92 & 54.05 & 42.76 \\
\hline Domestic credit provided by banking sector ( $\%$ of GDP) & 69.25 & 71.88 & 116.73 & 169.07 & 121.60 \\
\hline Product market Protection - Barrier to entrepreneurship & 2.27 & 2.04 & 2.44 & 2.74 & 1.59 \\
\hline Product market Protection - Barrier to trade and investments & 1.59 & 0.57 & 0.54 & 1.36 & 0.45 \\
\hline Domestic credit to private sector (\% of GDP) & 49.78 & 61.48 & 83.49 & 138.08 & 102.61 \\
\hline Public expenditure on education ( $\%$ on government expenditure) & 12.42 & 13.13 & 8.93 & 14.25 & 12.89 \\
\hline Employment protection & 2.78 & 2.44 & 2.87 & 2.18 & 1.48 \\
\hline Temporary employment protection & 1.45 & 1.88 & 3.14 & 1.98 & 0.41 \\
\hline Percentage of foreign banks among total banks (\%) & 40.00 & 4.25 & 17.67 & 8.67 & 33.50 \\
\hline Percentage of GERD financed by private sector & 49.10 & 57.33 & 52.67 & 75.99 & 55.52 \\
\hline Taxes on goods and services ( $\%$ total tax) & 36.63 & 32.27 & 27.40 & 25.99 & 26.91 \\
\hline Gross replacement ratio & 19.36 & 41.68 & 34.43 & 16.48 & 18.97 \\
\hline Net personal marginal tax rate: Principal earner $(\%)$ & 39.13 & 50.25 & 48.18 & 19.85 & 36.38 \\
\hline Marginal tax wedge: Principal earner (\%) & 52.04 & 57.28 & 59.96 & 26.20 & 41.93 \\
\hline Minimum wage/Median earning & 0.35 & 0.00 & 0.27 & 0.18 & 0.35 \\
\hline $\begin{array}{l}\text { Public expenditure on Passive Labour Market Policies ( } \% \text { on } \\
\text { GDP) }\end{array}$ & 1.28 & 2.88 & 1.99 & 0.53 & 0.91 \\
\hline Total public social expenditure (\% GDP) & 19.49 & 28.75 & 25.37 & 11.61 & 17.63 \\
\hline Public unemployment expenditure (\% GDP) & 1.39 & 2.93 & 1.85 & 0.54 & 0.93 \\
\hline Product market Protection - State Control & 3.42 & 2.80 & 3.48 & 2.94 & 1.83 \\
\hline Share of temporary employment & 12.35 & 14.50 & 8.69 & 15.83 & 6.99 \\
\hline Social security contributions ( $\%$ total tax) & 31.68 & 21.04 & 37.36 & 24.28 & 14.18 \\
\hline Gross domestic expenditure on R\&D (\% of GDP) & 0.82 & 2.26 & 1.77 & 2.59 & 1.92 \\
\hline Total researchers per thousand total employment & 3.37 & 7.49 & 5.33 & 6.82 & 6.77 \\
\hline Percentage of GERD financed by government & 44.98 & 36.72 & 40.83 & 22.94 & 37.47 \\
\hline Stock market capitalization to GDP (\%) & 16.85 & 39.79 & 33.77 & 76.00 & 80.04 \\
\hline Stock market total value traded to GDP $(\%)$ & 5.42 & 19.36 & 20.16 & 53.15 & 39.71 \\
\hline Stock market turnover ratio (value traded/capitalization) (\%) & 41.47 & 50.23 & 63.90 & 69.68 & 54.55 \\
\hline Total tax revenue on GDP & 35.36 & 45.70 & 41.06 & 24.45 & 31.40 \\
\hline Trade union density & 36.53 & 74.47 & 32.63 & 19.72 & 28.29 \\
\hline Taxes on income, profits and capital gains ( $\%$ total tax) & 28.10 & 43.07 & 28.76 & 37.31 & 46.19 \\
\hline Average Tax wedge (\%) & 40.30 & 45.15 & 49.13 & 21.17 & 31.78 \\
\hline Wage coordination & 2.43 & 3.50 & 3.67 & 4.00 & 1.25 \\
\hline Countries & $\begin{array}{r}\text { Czech R. } \\
\text { Slovakia } \\
\text { Portugal } \\
\text { Spain } \\
\text { Poland } \\
\text { Hungary } \\
\text { Ireland }\end{array}$ & $\begin{array}{r}\text { Finland } \\
\text { Sweden } \\
\text { Norway } \\
\text { Denmark }\end{array}$ & $\begin{array}{r}\text { Austria } \\
\text { Germany } \\
\text { Italy } \\
\text { France } \\
\text { Belgium } \\
\text { Netherl. }\end{array}$ & $\begin{array}{r}\text { Japan } \\
\text { Switzter. } \\
\text { Korea }\end{array}$ & $\begin{array}{r}\text { Australia } \\
\text { Canada } \\
\text { UK } \\
\text { USA }\end{array}$ \\
\hline
\end{tabular}


Table A.5: Between and within-cluster deviance, 1995

\begin{tabular}{|c|c|c|c|c|}
\hline Indicator & $\begin{array}{r}\text { Within } \\
\text { cluster } \\
\text { SS }\end{array}$ & $\begin{array}{r}\text { Between } \\
\text { cluster } \\
\text { SS }\end{array}$ & $\begin{array}{r}\text { Total } \\
\text { SS }\end{array}$ & $\begin{array}{r}\text { Between } \\
\text { SS } \\
\%\end{array}$ \\
\hline Total tax revenue on GDP & 260.16 & 1012.53 & 1272.69 & 79.6 \\
\hline Average Tax wedge (\%) & 649.32 & 1935.6 & 2584.92 & 74.9 \\
\hline Total public social expenditure (\% GDP) & 252.96 & 679.87 & 932.83 & 72.9 \\
\hline Gross domestic expenditure on R\&D (\% of GDP) & 3.71 & 9.23 & 12.94 & 71.3 \\
\hline Marginal tax wedge: Principal earner (\%) & 1263.6 & 2796.31 & 4059.91 & 68.9 \\
\hline Trade union density & 3348.25 & 6882.86 & 10231.11 & 67.3 \\
\hline Public expenditure on Active Labour Market Policies ( \% on GDP) & 2.02 & 4.14 & 6.16 & 67.2 \\
\hline Total researchers per thousand total employment & 33.91 & 59.36 & 93.27 & 63.6 \\
\hline Employment protection & 3.56 & 5.87 & 9.43 & 62.2 \\
\hline Wage coordination & 12.8 & 21.04 & 33.84 & 62.2 \\
\hline Average income tax rate (\%) & 575.25 & 933.89 & 1509.14 & 61.9 \\
\hline Product market Protection - State Control & 5.94 & 8.28 & 14.22 & 58.2 \\
\hline Stock market capitalization to GDP (\%) & 10330.06 & 14093.99 & 24424.05 & 57.7 \\
\hline Stock market total value traded to GDP (\%) & 4981.86 & 6108.8 & 11090.66 & 55.1 \\
\hline Taxes on income, profits and capital gains (\% total tax) & 1234.91 & 1343.67 & 2578.58 & 52.1 \\
\hline Net personal marginal tax rate: Principal earner (\%) & 1962.54 & 2093.91 & 4056.45 & 51.6 \\
\hline Social security contributions ( $\%$ total tax) & 1672.14 & 1613.43 & 3285.57 & 49.1 \\
\hline Domestic credit to private sector (\% of GDP) & 21075.79 & 20001.33 & 41077.12 & 48.7 \\
\hline Bank concentration (\%) & 4598.88 & 4334.67 & 8933.55 & 48.5 \\
\hline Public expenditure on Passive Labour Market Policies ( $\%$ on GDP) & 16.22 & 13.46 & 29.68 & 45.4 \\
\hline Gross replacement ratio & 2806.22 & 2183.49 & 4989.71 & 43.8 \\
\hline Temporary employment protection & 26.59 & 19.44 & 46.03 & 42.2 \\
\hline Domestic credit provided by banking sector ( $\%$ of GDP) & 39002.82 & 27453.69 & 66456.51 & 41.3 \\
\hline Product market Protection - Barrier to entrepreneurship & 4.21 & 2.88 & 7.09 & 40.6 \\
\hline Public unemployment expenditure (\% GDP) & 19.18 & 12.9 & 32.08 & 40.2 \\
\hline Percentage of foreign banks among total banks (\%) & 7185.75 & 4652.21 & 11837.96 & 39.3 \\
\hline Public expenditure on education (\% on government expenditure) & 128.23 & 81.42 & 209.65 & 38.8 \\
\hline Percentage of GERD financed by private sector & 2620.97 & 1605.51 & 4226.48 & 38.0 \\
\hline Taxes on goods and services (\% total tax) & 728.38 & 445.03 & 1173.41 & 37.9 \\
\hline Product market Protection - Barrier to trade and investments & 11.96 & 5.96 & 17.92 & 33.3 \\
\hline Percentage of GERD financed by government & 2204.99 & 1069.94 & 3274.93 & 32.7 \\
\hline Minimum wage/Median earning & 0.87 & 0.37 & 1.24 & 29.8 \\
\hline Share of temporary employment & 883.76 & 224.99 & 1108.75 & 20.3 \\
\hline Stock market turnover ratio (value traded/capitalization) (\%) & 11202.57 & 2482.16 & 13684.73 & 18.1 \\
\hline
\end{tabular}


Table A.6. Cluster averages for each indicator, 2010

\begin{tabular}{|c|c|c|c|c|c|c|}
\hline & \multicolumn{6}{|c|}{ CLUSTER } \\
\hline & 1 & 2 & 3 & 4 & 5 & 6 \\
\hline $\begin{array}{l}\text { Public expenditure on Active Labour Market Policies (\% } \\
\text { on GDP) }\end{array}$ & 0.40 & 0.75 & 0.91 & 0.70 & 0.32 & 0.20 \\
\hline Average income tax rate $(\%)$ & 10.18 & 13.53 & 22.37 & 20.85 & 6.07 & 16.13 \\
\hline Bank concentration $(\%)$ & 63.08 & 73.23 & 90.91 & 70.47 & 47.58 & 60.29 \\
\hline Domestic credit provided by banking sector (\% of GDP) & 65.45 & 204.32 & 136.19 & 135.07 & 215.54 & 192.14 \\
\hline PMR - Barrier to entrepreneurship & 1.78 & 1.14 & 1.16 & 1.25 & 1.25 & 1.11 \\
\hline PMR - Barrier to trade and investments & 0.79 & 0.17 & 0.37 & 0.54 & 0.96 & 0.23 \\
\hline Domestic credit to private sector ( $\%$ of GDP) & 54.67 & 186.77 & 133.22 & 111.61 & 136.60 & 165.72 \\
\hline $\begin{array}{l}\text { Public expenditure on education (\% on government } \\
\text { expenditure) }\end{array}$ & 10.36 & 10.71 & 13.98 & 10.86 & 12.59 & 13.35 \\
\hline Employment protection & 2.56 & 2.74 & 2.33 & 2.94 & 2.07 & 1.68 \\
\hline Temporary employment protection & 1.45 & 2.03 & 1.69 & 1.67 & 1.50 & 0.58 \\
\hline Percentage of foreign banks among total banks ( $\%)$ & 78.75 & 35.00 & 8.50 & 20.25 & 12.50 & 38.60 \\
\hline Percentage of GERD financed by private sector & 40.26 & 51.34 & 59.70 & 55.57 & 77.71 & 61.99 \\
\hline Taxes on goods and services (\% total tax) & 37.94 & 31.76 & 30.10 & 27.24 & 26.30 & 24.82 \\
\hline Gross replacement ratio & 8.72 & 35.41 & 33.80 & 24.10 & 10.41 & 19.76 \\
\hline Net personal marginal tax rate: Principal earner $(\%)$ & 35.36 & 33.83 & 40.59 & 49.89 & 23.87 & 32.89 \\
\hline Marginal tax wedge: Principal earner (\%) & 48.30 & 46.20 & 48.82 & 60.96 & 31.85 & 38.08 \\
\hline Minimum wage/Median earning & 0.43 & 0.51 & 0.00 & 0.13 & 0.39 & 0.37 \\
\hline $\begin{array}{l}\text { Public expenditure on Passive Labour Market Policies } \\
\text { (on GDP) }\end{array}$ & 0.51 & 2.14 & 1.21 & 1.61 & 0.35 & 0.63 \\
\hline Total public social expenditure (\% GDP) & 21.16 & 26.33 & 27.87 & 28.30 & 15.76 & 20.17 \\
\hline Public unemployment expenditure (\% GDP) & 0.73 & 2.04 & 1.35 & 1.83 & 0.39 & 0.68 \\
\hline PMR - State Control & 2.33 & 1.97 & 1.84 & 2.21 & 1.71 & 1.62 \\
\hline Share of temporary employment & 12.90 & 18.20 & 11.90 & 11.22 & 18.39 & 8.50 \\
\hline Social security contributions ( $\%$ total tax) & 38.60 & 32.29 & 19.85 & 34.32 & 31.96 & 16.76 \\
\hline Gross domestic expenditure on R\&D (\% of GDP) & 1.02 & 1.76 & 3.01 & 2.21 & 3.50 & 2.31 \\
\hline Total researchers per thousand total employment & 5.52 & 7.87 & 12.79 & 7.43 & 10.63 & 8.07 \\
\hline Percentage of GERD financed by government & 47.43 & 39.79 & 31.74 & 33.95 & 21.96 & 31.65 \\
\hline Stock market capitalization to GDP (\%) & 21.48 & 58.19 & 69.88 & 31.66 & 85.09 & 142.96 \\
\hline Stock market total value traded to GDP (\%) & 10.91 & 51.64 & 58.75 & 24.56 & 123.80 & 149.25 \\
\hline Stock market turnover ratio $(\%)$ & 43.77 & 76.27 & 85.94 & 101.10 & 135.71 & 102.86 \\
\hline Total tax revenue on GDP & 33.03 & 34.55 & 44.63 & 41.12 & 26.35 & 28.88 \\
\hline Trade union density & 16.42 & 18.81 & 65.37 & 33.25 & 13.98 & 20.07 \\
\hline Taxes on income, profits and capital gains ( $\%$ total tax) & 19.73 & 28.26 & 44.86 & 31.05 & 29.21 & 46.25 \\
\hline Average Tax wedge (\%) & 40.21 & 38.11 & 40.16 & 50.12 & 25.19 & 28.39 \\
\hline Wage coordination & 1.75 & 3.20 & 3.75 & 4.00 & 3.50 & 1.60 \\
\hline Countries & $\begin{array}{r}\text { Czech R. } \\
\text { Slovakia } \\
\text { Hungary } \\
\text { Poland }\end{array}$ & $\begin{array}{r}\text { Netherl. } \\
\text { Portugal } \\
\text { Spain } \\
\text { France } \\
\text { Ireland }\end{array}$ & $\begin{array}{r}\text { Finland } \\
\text { Sweden } \\
\text { Norway } \\
\text { Denmark }\end{array}$ & $\begin{array}{r}\text { Austria } \\
\text { Germany } \\
\text { Italy } \\
\text { Belgium }\end{array}$ & $\begin{array}{l}\text { Japan } \\
\text { Korea }\end{array}$ & $\begin{array}{r}\text { Canada } \\
\text { UK } \\
\text { Australia } \\
\text { USA } \\
\text { Switzerl. }\end{array}$ \\
\hline
\end{tabular}


Table A.7. Between and within-cluster deviance, 2010

\begin{tabular}{|c|c|c|c|c|}
\hline Indicator & $\begin{array}{r}\text { Within } \\
\text { cluster } \\
\text { SS } \\
\end{array}$ & $\begin{array}{r}\text { Between } \\
\text { cluster } \\
\text { SS } \\
\end{array}$ & $\begin{array}{r}\text { Total } \\
\text { SS }\end{array}$ & $\begin{array}{r}\text { Between } \\
\text { SS } \\
\% \\
\end{array}$ \\
\hline Trade union density & 1242.68 & 7358.54 & 8601.22 & 85.55 \\
\hline Gross replacement ratio & 638.43 & 2420.58 & 3059.01 & 79.13 \\
\hline Taxes on income, profits and capital gains (\% total tax) & 781.18 & 2281.47 & 3062.65 & 74.49 \\
\hline Stock market capitalization to GDP (\%) & 14765.9 & 43054.5 & 57820.4 & 74.46 \\
\hline Total tax revenue on GDP & 323.1 & 872.89 & 1195.99 & 72.98 \\
\hline Average Tax wedge (\%) & 572.14 & 1414.3 & 1986.44 & 71.20 \\
\hline Wage coordination & 10 & 22.63 & 32.63 & 69.35 \\
\hline Average income tax rate (\%) & 284.87 & 615.7 & 900.57 & 68.37 \\
\hline Total researchers per thousand total employment & 60.76 & 125.56 & 186.32 & 67.39 \\
\hline Minimum wage/Median earning & 0.4 & 0.81 & 1.21 & 66.94 \\
\hline Total public social expenditure (\% GDP) & 204.73 & 401.81 & 606.54 & 66.25 \\
\hline Public expenditure on Passive Labour Market Policies ( $\%$ on GDP) & 5.15 & 10.1 & 15.25 & 66.23 \\
\hline Marginal tax wedge: Principal earner (\%) & 846.88 & 1655.09 & 2501.97 & 66.15 \\
\hline Gross domestic expenditure on R\&D (\% of GDP) & 6.47 & 12.57 & 19.04 & 66.02 \\
\hline Stock market total value traded to GDP (\%) & 33794.62 & 61497.06 & 95291.68 & 64.54 \\
\hline Employment protection & 2.61 & 4.7 & 7.31 & 64.30 \\
\hline Domestic credit to private sector (\% of GDP) & 26084.03 & 46136.21 & 72220.24 & 63.88 \\
\hline Percentage of GERD financed by private sector & 1306.28 & 2276.71 & 3582.99 & 63.54 \\
\hline Percentage of foreign banks among total banks (\%) & 7280.2 & 12400.76 & 19680.96 & 63.01 \\
\hline Product market Protection - Barrier to entrepreneurship & 0.79 & 1.31 & 2.1 & 62.38 \\
\hline Public expenditure on Active Labour Market Policies ( $\%$ on GDP) & 1.24 & 1.62 & 2.86 & 56.64 \\
\hline Domestic credit provided by banking sector ( $\%$ of GDP) & 48006.35 & 61398.01 & 109404.4 & 56.12 \\
\hline Net personal marginal tax rate: Principal earner (\%) & 969.63 & 1205.71 & 2175.34 & 55.43 \\
\hline Bank concentration (\%) & 3040.21 & 3453.77 & 6493.98 & 53.18 \\
\hline Social security contributions ( $\%$ total tax) & 1437.73 & 1627.94 & 3065.67 & 53.10 \\
\hline Public expenditure on education (\% on government expenditure) & 46.01 & 49.58 & 95.59 & 51.87 \\
\hline Percentage of GERD financed by government & 1118.33 & 1167.98 & 2286.31 & 51.09 \\
\hline Taxes on goods and services (\% total tax) & 446.59 & 459.38 & 905.97 & 50.71 \\
\hline Product market Protection - Barrier to trade and investments & 1.77 & 1.67 & 3.44 & 48.55 \\
\hline Public unemployment expenditure (\% GDP) & 12.15 & 8.7 & 20.85 & 41.73 \\
\hline Stock market turnover ratio (value traded/capitalization) (\%) & 29259.99 & 14852.37 & 44112.36 & 33.67 \\
\hline Share of temporary employment & 633.41 & 311.93 & 945.34 & 33.00 \\
\hline Temporary employment protection & 12.12 & 5.9 & 18.02 & 32.74 \\
\hline Product market Protection - State Control & 5.02 & 1.55 & 6.57 & 23.59 \\
\hline
\end{tabular}




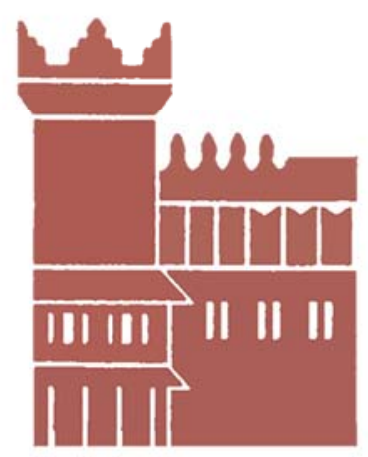

Alma Mater Studiorum - Università di Bologna DEPARTMENT OF ECONOMICS

Strada Maggiore 45

40125 Bologna - Italy

Tel. +39051 2092604

Fax +390512092664

http://www.dse.unibo.it 